\title{
Cytosolic Calcium Coordinates Mitochondrial Energy Metabolism with Presynaptic Activity
}

\author{
Amit K. Chouhan, ${ }^{1}$ Maxim V. Ivannikov, ${ }^{1}$ Zhongmin Lu, ${ }^{1}$ Mutsuyuki Sugimori, ${ }^{2}$ Rodolfo R. Llinas, ${ }^{2}$ \\ and Gregory T. Macleod ${ }^{1}$ \\ ${ }^{1}$ Department of Physiology, University of Texas Health Science Center at San Antonio, San Antonio, Texas 78229, and ${ }^{2}$ Department of Physiology and \\ Neuroscience, New York University School of Medicine, New York, New York 10016
}

\begin{abstract}
Most neurons fire in bursts, imposing episodic energy demands, but how these demands are coordinated with oxidative phosphorylation is still unknown. Here, using fluorescence imaging techniques on presynaptic termini of Drosophila motor neurons (MNs), we show that mitochondrial matrix $\mathrm{pH}\left(\mathrm{pH}_{\mathrm{m}}\right)$, inner membrane potential $\left(\Delta \psi_{\mathrm{m}}\right)$, and $\mathrm{NAD}(\mathrm{P}) \mathrm{H}$ levels $\left([\mathrm{NAD}(\mathrm{P}) \mathrm{H}]_{\mathrm{m}}\right)$ increase within seconds of nerve stimulation. The elevations of $\mathrm{pH}_{\mathrm{m}}, \Delta \psi_{\mathrm{m}}$, and $[\mathrm{NAD}(\mathrm{P}) \mathrm{H}]_{\mathrm{m}}$ indicate an increased capacity for ATP production. Elevations in $\mathrm{pH}$ blocked by manipulations that blocked mitochondrial $\mathrm{Ca}^{2+}$ uptake, including replacement of extracellular $\mathrm{Ca}^{2+}$ with Sr$^{2+}$ and application of either tetraphenylphosphonium chloride or KB-R7943, indicating that it is $\mathrm{Ca}^{2+}$ that stimulates presynaptic mitochondrial energy metabolism. To place this phenomenon within the context of endogenous neuronal activity, the firing rates of a number of individually identified MNs were determined during fictive locomotion. Surprisingly, although endogenous firing rates are significantly different, there was little difference in presynaptic cytosolic $\mathrm{Ca}^{2+}$ levels $\left(\left[\mathrm{Ca}^{2+}\right]_{\mathrm{c}}\right)$ between MNs when each fires at its endogenous rate. The average $\left[\mathrm{Ca}^{2+}\right]_{\mathrm{c}}$ level $(329 \pm 11 \mathrm{~nm})$ was slightly above the average $\mathrm{Ca}^{2+}$ affinity of the mitochondria $(281 \pm 13 \mathrm{~nm})$. In summary, we show that when $\mathrm{MNs}$ fire at endogenous rates, $\left[\mathrm{Ca}^{2+}\right]_{\mathrm{c}}$ is driven into a range where mitochondria rapidly acquire $\mathrm{Ca}^{2+}$. As we also show that $\mathrm{Ca}^{2+}$ stimulates presynaptic mitochondrial energy metabolism, we conclude that $\left[\mathrm{Ca}^{2+}\right]_{\mathrm{c}}$ levels play an integral role in coordinating mitochondrial energy metabolism with presynaptic activity in Drosophila MNs.
\end{abstract}

\section{Introduction}

While neural activity never ceases, the activity of individual neurons can be highly variable (Kumar et al., 2010). Neurons, therefore, have variable ATP demands, and the variability must be accommodated as low levels of ATP would threaten the fidelity of neurotransmission. The excitability of neuronal membranes relies on $\mathrm{Na}^{+} / \mathrm{K}^{+}$gradients maintained by $\mathrm{Na}, \mathrm{K}-\mathrm{ATP}$ ases, and excitability can also be modulated by ATP-sensitive $\mathrm{K}^{+}$-channels (Haller et al., 2001). Furthermore, the release of neurotransmitter itself is sustained by ATP, which is used to reload and recycle synaptic vesicles and to clear $\mathrm{Ca}^{2+}$ from presynaptic termini (Attwell and Laughlin, 2001). As most nerve termini are characterized by a relatively small cytosolic volume, it is unlikely that the ATP bound by cytosolic ATP binding proteins provides sufficient reserve for any appreciable period of time in the absence of active ATP regeneration from ADP or AMP. It follows that in nerve

Received March 14, 2011; revised Nov. 8, 2011; accepted Nov. 10, 2011.

Author contributions: A.K.C., M.V.I., Z.L., M.S., R.R.L., and G.T.M. designed research; A.K.C., M.V.I., Z.L., M.S., R.R.L., and G.T.M. performed research; A.K.C., M.V.I., Z.L., and G.T.M. analyzed data; G.T.M. wrote the paper.

This study was supported by a grant from the National Institute of Neurological Disorders and Stroke to GTM [National Institutes of Health (NIH) R01 NS061914]. We thank Bloomington Drosophila Stock Center, Vienna Drosophila RNAi Center, Benjamin Eaton, and Loren Looger for providing fly strains, Tullio Pozzan for providing plasmids, Rosario Martinez for assistance preparing CDNA and maintaining fly stocks, William Morgan for advice on statistical analysis, and Balaji lyengar, Monica Maldonado, Rene Renteria, and Adam Rossano for critical comments on this manuscript.

Correspondence should be addressed to Gregory T. Macleod, Department of Physiology, University of Texas Health Science Center at San Antonio, 7703 Floyd Curl Drive, San Antonio TX 78229. E-mail: macleod@uthscsa.edu. DOI:10.1523/JNEUROSCI.1301-11.2012

Copyright $\odot 2012$ the authors $\quad 0270-6474 / 12 / 321233-11 \$ 15.00 / 0$ termini capable of sustaining high rates of neurotransmitter release, the ATP production machinery must be highly responsive to nerve activity. Mitochondria accumulate within motor neuron (MN) termini (Yoshikami and Okun, 1984), and so it is likely that most of the ATP is supplied by oxidative phosphorylation and that oxidative phosphorylation, in addition to glycolysis, is called upon to accommodate variable demands in ATP. Indeed, MN termini without functional mitochondria fail to maintain $\mathrm{Ca}^{2+}$ homeostasis or sustain neurotransmitter release during prolonged activity (David and Barrett, 2003; Guo et al., 2005; Verstreken et al., 2005; Chouhan et al., 2010).

Classic studies on isolated mitochondria demonstrated that an increase in the ADP:ATP ratio stimulated oxidative phosphorylation (Chance and Williams, 1955). Within a cellular environment, this ratio has been proposed to integrate ATP supply with demand (Erecińska and Wilson, 1982). Over the last two decades, $\mathrm{Ca}^{2+}$ has been gathering recognition for its ability to stimulate oxidative phosphorylation via $\mathrm{Ca}^{2+}$-sensitive intramitochondrial dehydrogenases (Denton, 2009), $\mathrm{F}_{1} \mathrm{~F}_{0}$-ATPases (Territo et al., 2000), and perhaps the adenine nucleotide transporter (Moreno-Sánchez, 1985). $\mathrm{Ca}^{2+}$ has been described as a metabolic integrator in hepatocytes and cardiomyocytes (Robb-Gaspers et al., 1998; Balaban, 2002). In cardiomyocytes, mitochondria accumulate $\mathrm{Ca}^{2+}$ in proportion to work done by the muscle, taking up $\mathrm{Ca}^{2+}$ with each cytosolic $\mathrm{Ca}^{2+}$ transient that drives excitation-contraction coupling. This $\mathrm{Ca}^{2+}$ then stimulates oxidative phosphorylation, thus coordinating ATP production with demand (Cortassa et al., 2003). It has also been suggested that $\mathrm{Ca}^{2+}$ coordinates mitochondrial 
metabolism with energy demands in neurons (Kann and Kovacs, 2007). For example, the stimulatory influence of $\mathrm{Ca}^{2+}$ on mitochondrial metabolism has been described in dissociated mouse neurons (Duchen, 1992), the cerebellar cortex in vivo (Reinert et al., 2004), and the neurohypophysis (Kosterin et al., 2005). However, the stimulatory influence of $\mathrm{Ca}^{2+}$ has not been detected at individually identified nerve termini where its relevance might be tested within the context of endogenous activity.

Here, we used fluorescence imaging techniques on Drosophila larval MN termini in situ and collected evidence of a $\mathrm{Ca}^{2+}$ dependent increase in mitochondrial energy metabolism that was evoked by nerve activity. Since presynaptic $\left[\mathrm{Ca}^{2+}\right]_{\mathrm{c}}$ varies in proportion to firing rate and native firing patterns raise $\left[\mathrm{Ca}^{2+}\right]_{\mathrm{C}}$ into a range where mitochondria acquire $\mathrm{Ca}^{2+}$, we propose that these $\mathrm{MN}$ termini harness the $\mathrm{Ca}^{2+}$ sensitivity of mitochondrial energy metabolism to coordinate presynaptic energy demands with oxidative phosphorylation. Interestingly, it appears that this coordination mechanism has been accommodated in different MN termini. The apparent mitochondrial affinities for $\mathrm{Ca}^{2+}$ are similar in different MN termini, yet despite a twofold difference in firing rates across $\mathrm{MNs}$ during fictive locomotion, presynaptic cytosolic $\mathrm{Ca}^{2+}$ levels are limited to a narrow range $(\sim 330 \mathrm{nM})$, marginally in excess of the mitochondrial affinity for $\mathrm{Ca}^{2+}$ ( $280 \mathrm{nM})$.

\section{Materials and Methods}

Fly stocks. Flies were raised on standard medium with dry yeast at $25^{\circ} \mathrm{C}$. The $w^{1118}$ strain was used as the wild-type control. We used enhancertrap strains OK6-GAL4 (Aberle et al., 2002) and elav-GAL4 (Lin and Goodman, 1994) to drive expression of transgenes in motor neurons. Bloomington Drosophila Stock Center (Bloomington, IN) provided UAS-DsRed (stock no. 6282; cytosolic) and UAS-EGFP (stock no. 6874; cytosolic) transgenic flies. Transgenic UAS-GCaMP3 flies were a gift from Loren Looger (Janelia Farm Research Campus, Ashburn, VA). Flies carrying the UAS-interference RNA construct to knock down CG4589 (Letm1) (transformant no. 6662) was obtained from the Vienna Drosophila RNAi Center (Dietzl et al., 2007). Transgenic UAS-mito-RP [ratiometric pericam (RP) targeted to the mitochondrial matrix (mito)] flies were described previously (Chouhan et al., 2010).

Solutions and chemicals. Unless indicated otherwise, chemicals were purchased from Sigma-Aldrich. Bongkrekic acid (catalog no. BMLCM113) was purchased from Enzo Life Sciences. KB-R7943 mesylate (catalog no. 1244) was purchased from Tocris Bioscience. Tetraphenylphosphonium chloride $\left(\mathrm{TPP}^{+}\right.$; catalog no.88060) was purchased from Fluka Analytical (Sigma-Aldrich). Tetramethylrhodamine ethyl ester (TMRE; catalog no.T669), DMSO (with 20\% pluronic acid; catalog no. P3000MP), synthetic $\mathrm{Ca}^{2+}$-reporters (rhod-FF AM, mag-Fluo-4 AM, fura-dextran, and rhod-dextran; catalog nos. R23983, M14206, F3029, and R34677, respectively), and AF647-dextran (catalog no. D22914) were obtained from Invitrogen. Hemolymph-like solution no.6 (HL6) containing $15 \mathrm{~mm} \mathrm{Mg}^{2+}$ and buffered to $\mathrm{pH} 7.3$ was used in all experiments (Macleod et al., 2002).

Generation of mtAlpHi transgenic flies. The genetically encoded mitochondrial $\mathrm{pH}$ reporter, $\mathrm{mtAlpHi}$, was expressed under the control of the GAL4/UAS system in MNs (Brand and Perrimon, 1993). cDNA for mtAlpHi was provided by Tullio Pozzan (University of Padua, Padua, Italy). MtAlpHi was targeted to the matrices of mitochondria using a tandem repeat of the first 36 aa of subunit VIII of human cytochrome oxidase (2mt8; Filippin et al., 2005). cDNA encoding this duplicate targeting sequence was fused in frame $5^{\prime}$ to the $\mathrm{N}$ terminus of the cDNA for mtAlpHi, cloned into a P-element vector (pUAST; Drosophila Genetic Resource Center, Bloomington, IN), and injected into $w^{1118}$ Drosophila embryos by Rainbow Transgenics Flies. Strains homozygous for transgene inserts were obtained after determining the chromosome harboring the transgene through standard genetic crosses involving the use of balancer chromosomes and out-crossing all other chromosomes to the $w^{1118}$ strain.
Wide-field $\mathrm{Ca}^{2+}$ imaging. Imaging of fluorescent $\mathrm{Ca}^{2+}$ reporters, $\mathrm{pH}$ reporters, and TMRE was performed using wide-field microscopy on an Olympus BX51WI microscope fitted with a $100 \times$ water-immersion objective (1.0 numerical aperture). A Sutter Instrument $150 \mathrm{~W}$ DG4 fluorescence excitation system was used to select excitation wavelengths, while a Sutter Instrument Lambda 10-B filter wheel, placed before an Andor Technology EMCCD camera (DU860), was used to filter emitted fluorescence. Filters and dichroic mirrors were provided by Chroma Technology or Semrock. The imaging system was controlled through an Andor Technology PCU100 and a Dell PC running Andor IQ software (ver.1.8). Neutral density filters were used to reduce excitation intensity to $3.1,6.3$, or $12.5 \%$.

To stimulate axons leading to the MN termini, the segmental nerve was cut close to the ventral ganglion and drawn into the lumen of a glass micropipette. Individual stimulus impulses, sufficient to elicit action potentials, were $300 \mu$ s in duration and $2.4 \mathrm{~V}$ in amplitude and delivered by a model DS2A Mk.II stimulator (Digitimer). Stimulus trains were triggered by a Master- 8 stimulator (A.M.P.I.). $\mathrm{Ca}^{2+}$ imaging was performed in HL6 containing $7 \mathrm{~mm}$ L-glutamic acid to desensitize postsynaptic glutamate receptors and eliminate muscle contraction.

Fura-dextran, a high-affinity $\left(K_{\mathrm{D}}=594 \mathrm{~nm}\right.$ in vitro $) \mathrm{Ca}^{2+}$ reporter conjugated to $10,000 \mathrm{MW}$ dextran, was used to measure the concentration of free $\mathrm{Ca}^{2+}$ in the cytosol $\left(\left[\mathrm{Ca}^{2+}\right]_{c}\right)$. Fura was forward filled into termini by cutting the segmental nerve of a dissected larva and exposing the cut end to a mixture of HL6 or Schneider's insect medium with $5 \mathrm{~mm}$ fura in distilled water. After $\sim 40 \mathrm{~min}$, fura was rinsed off and allowed to equilibrate in the axon for $>60 \mathrm{~min}$ (Macleod et al., 2002). Fura fluorescence was examined using alternating $340 / 26$ and $387 / 11 \mathrm{~nm}$ excitation filters, a $409 \mathrm{~nm}$ dichroic mirror, and a 510/84 nm emission filter. Fluorescence signals were converted to $\left[\mathrm{Ca}^{2+}\right]$ using the Equation 5 of Grynkiewicz et al. (1985). Values of $R_{\max }$ were obtained in situ through incubation of preparations in HL6 containing $10 \mathrm{mM} \mathrm{Ca}^{2+}$ and $100 \mu \mathrm{M}$ ionomycin (catalog no. 19657; Sigma) for $30 \mathrm{~min}$. Values of $R_{\min }$ were obtained through incubation of preparations in $\mathrm{Ca}^{2+}$-free HL6 with 1 mM EGTA and $100 \mu \mathrm{M}$ BAPTA-AM (1\% DMSO) for $20 \mathrm{~min}$ (catalog no. B6769; Invitrogen) (Chouhan et al., 2010). The $K_{\mathrm{D}}$ value used for furadextran was $865 \mathrm{~nm}$ (Tank et al., 1995).

Rhod-dextran, a low-affinity 10,000 MW dextran-conjugated $\mathrm{Ca}^{2+}$ reporter $\left(K_{\mathrm{D}}=3.0 \mu \mathrm{M}\right)$, was forward filled as described in the above paragraph and examined using a 543/22 nm excitation filter, a $552 \mathrm{~nm}$ dichroic mirror and a 593/40 nm emission filter. As rhod-dextran is almost invisible at resting $\left[\mathrm{Ca}^{2+}\right]_{\mathrm{c}}, \mathrm{AF} 647$-dextran, a Ca ${ }^{2+}$-insensitive dextran-conjugated fluorophore (10,000 MW), was also forward filled. AF647-dextran was examined using a 628/40 nm exciter filter, a $660 \mathrm{~nm}$ dichroic mirror and a 692/40 nm emission filter.

Loading of synthetic mitochondrial $\mathrm{Ca}^{2+}$-reporters. Rhod-FF and magFluo- 4 were loaded by bath application of the acetoxymethyl (AM) form of the $\mathrm{Ca}^{2+}$-reporters to a larval preparation with uncut segmental nerves. A 2 mm stock was made in 100\% DMSO/20\% pluronic acid. This was diluted to $5 \mu \mathrm{M}(0.25 \% \mathrm{DMSO} / 0.05 \%$ pluronic acid $)$ in HL6, applied to the preparation at room temperature, and incubated in the dark for 10 min. To clear the $\mathrm{Ca}^{2+}$ reporter from the cytosol, the preparation was then rinsed in $\mathrm{Ca}^{2+}$ reporter-free chilled HL6 and incubated for at least $30 \mathrm{~min}$ before imaging. HL6 was replaced every $30 \mathrm{~min}$ during this incubation, and nerves were cut and drawn into a stimulating pipette at least 20 min before imaging.

TMRE imaging. Changes in mitochondrial membrane potential were measured as changes in mitochondrial TMRE fluorescence in the nonquench mode (Scaduto and Grotyohann, 1999). The preparation was exposed to $50 \mathrm{~nm}$ TMRE in chilled Schneider's (0.0005\% DMSO/ $0.0001 \%$ pluronic acid), placed in the dark at room temperature for 7 min, and then rinsed in chilled Schneider's. The preparation was kept in the dark until required for imaging, and during this period (30-300 min) Schneider's was replaced every $30 \mathrm{~min}$. TMRE was excited using a 543/22 $\mathrm{nm}$ bandpass filter via a $562 \mathrm{~nm}$ dichroic mirror, and fluorescence was viewed through a 593/40 nm emission filter. Because TMRE is washed from the preparation, it is unlikely that any increase in mitochondrial fluorescence is due to continued TMRE loading. TMRE will slowly leak from termini over time, resulting in a decrease in mitochondrial TMRE 
fluorescence, and an underestimate of $\Delta \psi_{\mathrm{m}}$ if TMRE is used to monitor $\Delta \psi_{\mathrm{m}}$ over extended periods. In this study, TMRE is only used to monitor $\Delta \psi_{\mathrm{m}}$ over periods of tens of seconds. Changes in the potential of the plasma membrane will also influence the amount of TMRE available to mitochondria (Ward et al., 2007). However, the MN membrane will recover to a similar potential after activity, making a similar amount of TMRE available to mitochondria afterward. To the extent that these MNs might hyperpolarize after activity, the amount of TMRE available to mitochondria will decrease, leading to an underestimate of $\Delta \psi_{\mathrm{m}}$.

$N A D(P) H$ imaging. Two-photon microscopy was performed on a custom-built system based on an Olympus AX70 microscope frame that was coupled to diode pumped Millena X and Tsunami Ti:sapphire lasers. The laser system generated pulses with a frequency of $80 \mathrm{MHz}$ and a duration of $70 \mathrm{fs}$. The laser scanning unit $(6215 \mathrm{H}$, Cambridge Technology) was controlled by a custom-written algorithm through a LabVIEW interface (version 7, National Instruments). A $730 \mathrm{~nm}$ excitation wavelength was selected by a group velocity dispersion prism. Average pixel dwell time was $2 \mu \mathrm{s}$. The emission signal was detected with a photomultiplier tube (H7732 MOD2, Hamamatsu Photonics). NAD(P)H fluorescence was filtered using a HQ430/25 filter (NC042339, Chroma Technology). Laser power output was tuned to $3 \mathrm{~mW}$ at the nosepiece of the objective ( $60 \times$ Olympus water immersion; 0.90 numerical aperture).

Image analysis. All images were analyzed using Andor IQ software or ImageJ (http://rsbweb.nih.gov/ij/). Briefly, to obtain the background value for each image, average pixel intensity was calculated for regions of interest not containing a MN axon terminal or structures that change in fluorescence in response to nerve stimulation. To obtain the fluorescence value (F) for each image, the background value was subtracted from the average pixel intensity value calculated for regions of interest containing several boutons along an identified terminal. In most cases, values of $\mathrm{F}$ were scaled between 0 and 1 , with 0 as the average value immediately before stimulation and 1 being the maximum stimulated response. Unless indicated, values of $\mathrm{F}$ were not corrected for bleaching. Where bleaching was corrected, a monoexponential fit was fitted to prestimulus values ( $\geq 12 \mathrm{~s}$ ), and this fit was used to correct $\mathrm{F}$ for the entire image series.

Electrophysiology. All experiments were performed on fillet-dissected wandering third instar larvae ( $w^{1118}$ strain) pinned on Sylgard (Dow Corning). Electrophysiological measurements were made within $30 \mathrm{~min}$ of dissection in HL6 containing $\mathrm{Ca}^{2+}$ but no L-glutamic acid. Recordings were made under the $20 \times$ water immersion objective of a BX51 Olympus microscope (200× magnification), allowing unequivocal identification of body wall muscles 7, 6, 13, 12, and 4 in abdominal segment 4 (Hoang and Chiba, 2001). Micropipettes were filled with a 1:1 mixture of $3 \mathrm{M} \mathrm{KCl}$ and $3 \mathrm{M} \mathrm{K}$-acetate to give a final resistance of $\sim 50 \mathrm{M} \Omega$. Each electrode was connected to an Axoclamp 900A amplifier through 0.1 or 1.0 gain headstages (Molecular Devices). Data were digitized (4/30, PowerLab) and acquired with Chart 5.5.6 software (AD Instruments). Data were analyzed using Chart software.

To quantify firing frequencies during fictive locomotion, segmental nerves were left intact and micropipette tips were placed into muscle fiber pairs as listed in Figure $3 A$. Due to strong muscle contractions during fictive locomotion, it was often difficult to maintain long-lasting paired micropipette recordings. Hence, records were accepted for analysis even if one or both muscle resting membrane potentials fell as low as $-30 \mathrm{mV}$ during rhythmic activity. Because we were quantifying a presynaptic phenomenon and excitatory junction potentials (EJPs) at high $\mathrm{Ca}^{2+}$ can be unambiguously resolved from the baseline, it is unlikely that accepting such data could compromise the conclusions drawn from our analysis. MNs contributing EJPs were identified as described previously (Chouhan et al., 2010).

Statistical analysis and data presentation. Sigma Stat (version 3.5; Systat Software) was used for statistical analysis. For pairwise comparisons, Student's $t$ tests were used. For multiple comparisons, ANOVA with post hoc Holm-Sidak or Tukey's tests were used as indicated. When data were found to be not normally distributed (Kolmogorov-Smirnov test), analogous nonparametric tests were used unless a two-way ANOVA was required, in which case data were transformed and re- tested. Associations were tested by calculating Pearson's Product Moment Correlation coefficient. Differences were considered to be statistically significant at $\alpha$ values of $p<0.05$. Values are reported as mean \pm SEM. Figures were generated in SigmaPlot (version 10; Systat Software ) and imported to Canvas (version X; ACD Systems) for panel assembly and labeling.

\section{Results}

\section{Presynaptic mitochondrial energy metabolism is stimulated by nerve activity}

Presynaptic mitochondria in Drosophila motor neurons acquire $\mathrm{Ca}^{2+}$ when trains of electrical impulses are applied to transected nerves (Fig. $1 \mathrm{~A}$ ). Mitochondrial $\mathrm{Ca}^{2+}$ acquisition can be detected using either synthetic (Fig. $1 B-D$ ) or genetically encoded $\mathrm{Ca}^{2+}$-reporters (Fig. $1 \mathrm{E}$; blue trace), targeted to the matrices of presynaptic mitochondria (see also Guo et al., 2005; Chouhan et al., 2010). When axon firing is driven at high rates $(80 \mathrm{~Hz})$, the mitochondrial free $\mathrm{Ca}^{2+}$ level $\left(\left[\mathrm{Ca}^{2+}\right]_{\mathrm{m}}\right)$ reaches close to its maximum within $\sim 0.5 \mathrm{~s}$, regardless of the identity of the mitochondrial $\mathrm{Ca}^{2+}$ reporter or the duration of the impulse train (Fig. $1 C-E$ ). Having previously established that mitochondrial $\mathrm{Ca}^{2+}$ uptake does not limit cytosolic free $\mathrm{Ca}^{2+}$ levels in these termini (Chouhan et al., 2010), we hypothesized that mitochondrial $\mathrm{Ca}^{2+}$ uptake serves to stimulate oxidative phosphorylation or, more generally, mitochondrial energy metabolism. Through the application of synthetic and genetically encoded fluorescent reporters, along with $\mathrm{NAD}(\mathrm{P}) \mathrm{H}$ imaging, we examined the impact of nerve stimulation on three different measures of mitochondrial energy metabolism: mitochondrial matrix $\mathrm{pH}\left(\mathrm{pH}_{\mathrm{m}}\right.$; Fig. $\left.1 E, F\right)$, inner mitochondrial membrane (IMM) potential $\left(\Delta \psi_{\mathrm{m}}\right.$; Fig. $\left.1 G\right)$, and mitochondrial $\mathrm{NAD}(\mathrm{P}) \mathrm{H}$ levels $\left([\mathrm{NAD}(\mathrm{P}) \mathrm{H}]_{\mathrm{m}}\right.$; Fig. $\left.1 H, I\right)$.

The proton gradient across the IMM $(\Delta \mathrm{pH})$ is a significant component of the proton motive force $(\Delta p)$ used by the $\mathrm{F}_{1} \mathrm{~F}_{0^{-}}$ ATPase to generate ATP (Nicholls and Ferguson, 2002). Changes in $\mathrm{pH}_{\mathrm{m}}$ were monitored in large bouton (type-Ib) axon termini of MN innervating muscle 13 (MN13Ib). Two genetically encoded fluorescent reporters were used: mito-RP (Fig. $1 E$ ) and mtAlphi (Fig. $1 F$ ). Mito-RP reports changes in both $\mathrm{pH}_{\mathrm{m}}$ and $\left[\mathrm{Ca}^{2+}\right]_{\mathrm{m}}$ with excitation wavelengths of 470 (or 490) and $420 \mathrm{~nm}$, respectively (Nagai et al., 2001; Filippin et al., 2003; Jiang et al., 2009). MtAlphi only reports changes in $\mathrm{pH}_{\mathrm{m}}$ (Abad et al., 2004; Wiederkehr et al., 2009). In response to nerve stimulation, both reporters showed a transient spike in $\mathrm{pH}_{\mathrm{m}}$ followed by a longlasting elevation in $\mathrm{pH}_{\mathrm{m}}$ (i.e., the matrix becomes alkaline) (Fig. $1 E, F$ ).

The electrical gradient across the IMM $\left(\Delta \psi_{\mathrm{m}}\right)$ represents the $\mathrm{Ca}^{2+}$ sequestration driving force and the major component of $\Delta p$. Changes in $\Delta \psi_{\mathrm{m}}$ were monitored as changes in the fluorescence of TMRE (Fig. 1G), a molecule that distributes across the IMM in Nernstian fashion (Scaduto and Grotyohann, 1999). When used in nonquench mode, as used here, an increase in TMRE fluorescence indicates an increase in $\Delta \psi_{\mathrm{m}}$. TMRE-loaded mitochondria responded to nerve stimulation with a rapid decrease in fluorescence $(6.5 \pm 1.2 \%)$, followed by a sustained elevation that peaked $\sim 15 \mathrm{~s}$ after the onset of stimulation (5.4 \pm $2.0 \%$ above baseline; mean \pm SEM; $n=6$ ).

Another measure of mitochondrial metabolic function is $\mathrm{NAD}(\mathrm{P}) \mathrm{H}$ autofluorescence (Kann et al., 2003). NAD(P)H carries reducing equivalents to complex I of the electron transport chain (ETC), and an increase in $\mathrm{NAD}(\mathrm{P}) \mathrm{H}$ autofluorescence indicates an increase in tricarboxylic acid cycle activity (when ETC activity is not inhibited). Within seconds of the start of the nerve 
stimulus train, $\mathrm{NAD}(\mathrm{P}) \mathrm{H}$ autofluorescence from presynaptic mitochondria increased significantly ( $\sim 12 \%$ at 15 s; Fig. $1 H, I)$, consistent with mitochondrial $\mathrm{Ca}^{2+}$ uptake stimulating tricarboxylic acid cycle activity. A comparison of the time courses of changes in $[\mathrm{NAD}(\mathrm{P}) \mathrm{H}]_{\mathrm{m}}$, $\left[\mathrm{Ca}^{2+}\right]_{\mathrm{m}}, \mathrm{pH}_{\mathrm{m}}$, and $\Delta \psi_{\mathrm{m}}$ in Figure 1 shows that changes in $[\mathrm{NAD}(\mathrm{P}) \mathrm{H}]_{\mathrm{m}}$ follow changes in $\left[\mathrm{Ca}^{2+}\right]_{\mathrm{m}}$ and parallel changes in $\mathrm{pH}_{\mathrm{m}}$ and $\Delta \psi_{\mathrm{m}}$.

An increase in $\mathrm{pH}_{\mathrm{m}}, \Delta \psi_{\mathrm{m}}$, or [NAD$(\mathrm{P}) \mathrm{H}]_{\mathrm{m}}$ alone may not indicate an increase in oxidative phosphorylation; however, a coordinated change in all three parameters is strong evidence of an increase in oxidative phosphorylation and an elevated capacity for mitochondrial ATP production.

\section{$\mathrm{Ca}^{2+}$ stimulates presynaptic} mitochondrial energy metabolism Removal of $\mathrm{Ca}^{2+}$ from the saline abolishes nerve stimulus-evoked changes in $\left[\mathrm{Ca}^{2+}\right]_{\mathrm{c}},\left[\mathrm{Ca}^{2+}\right]_{\mathrm{m}}, \mathrm{pH}_{\mathrm{m}}$ (Fig. $2 A$ ), and $\Delta \psi_{\mathrm{m}}$ (Fig. 2B). To test the hypothesis that $\mathrm{Ca}^{2+}$ itself stimulates mitochondrial energy metabolism, we replaced $\mathrm{Ca}^{2+}$ with $\mathrm{Sr}^{2+}$, as mitochondria accumulate $\mathrm{Sr}^{2+}$ (Greenawalt and Carafoli, 1966) but $\mathrm{Sr}^{2+}$ is tenfold less effective than $\mathrm{Ca}^{2+}$ at stimulating dehydrogenases in isolated rat heart mitochondria (McCormack and Osbaldeston, 1990). $\mathrm{CaCl}_{2}$ was omitted from the saline, and $\mathrm{SrCl}_{2}$ was added to 4 mM along with EGTA to $2 \mathrm{~mm}$ (effective extracellular $\mathrm{Sr}^{2+}$ concentration $\geq 2 \mathrm{mM}$ ). Upon nerve stimulation, mito-RP fluorescence decreased under $420 \mathrm{~nm}$ excitation $\left(\mathrm{Ca}^{2+}\right.$-sensitive wavelength), indicating that ratiometric pericam is sensitive to $\mathrm{Sr}^{2+}$ and that presynaptic mitochondria take up $\mathrm{Sr}^{2+}$ (Fig. 2C, first section, and $D$ ). However, the increase in $\mathrm{pH}_{\mathrm{m}}$ in $\geq 2 \mathrm{mM}$ $\mathrm{Sr}^{2+}(4.2 \% \pm 0.6 \%, n=5)$ was significantly less than that seen in $2 \mathrm{mM} \mathrm{Ca}^{2+}$ $(12.5 \% \pm 1.9 \%, n=4$; mean \pm SEM $)$. Tetraphenylphosphonium $\left(\mathrm{TPP}^{+}\right)$and KBR7943, which block mitochondrial $\mathrm{Ca}^{2+}$ uptake, were also used to test the dependence of matrix alkalinization on $\mathrm{Ca}^{2+}$ uptake (Fig. $2 C$, second and third section). $\mathrm{TPP}^{+}$inhibits mitochondrial $\mathrm{Ca}^{2+}$ uptake and release (Wingrove and Gunter, 1986; Tang and Zucker, 1997), while KB-R7943 inhibits the mitochondrial $\mathrm{Ca}^{2+}$ uniporter (Santo-Domingo et al., 2007). These compounds completely blocked mitochondrial $\mathrm{Ca}^{2+}$ uptake. At the same time, they depressed basal $\mathrm{pH}_{\mathrm{m}}$ levels (became acidic) and blocked all nerve stimulation evoked elevations in $\mathrm{pH}_{\mathrm{m}}$ (Fig. 2D).

The data above strengthen the hypothesis that $\mathrm{Ca}^{2+}$ is instrumental in stimulating mitochondrial energy metabolism. However, as it is commonly accepted that an increase in the ADP:ATP ratio can stimulate oxidative phosphorylation, the possibility remains that under the conditions of each manipulation above, the
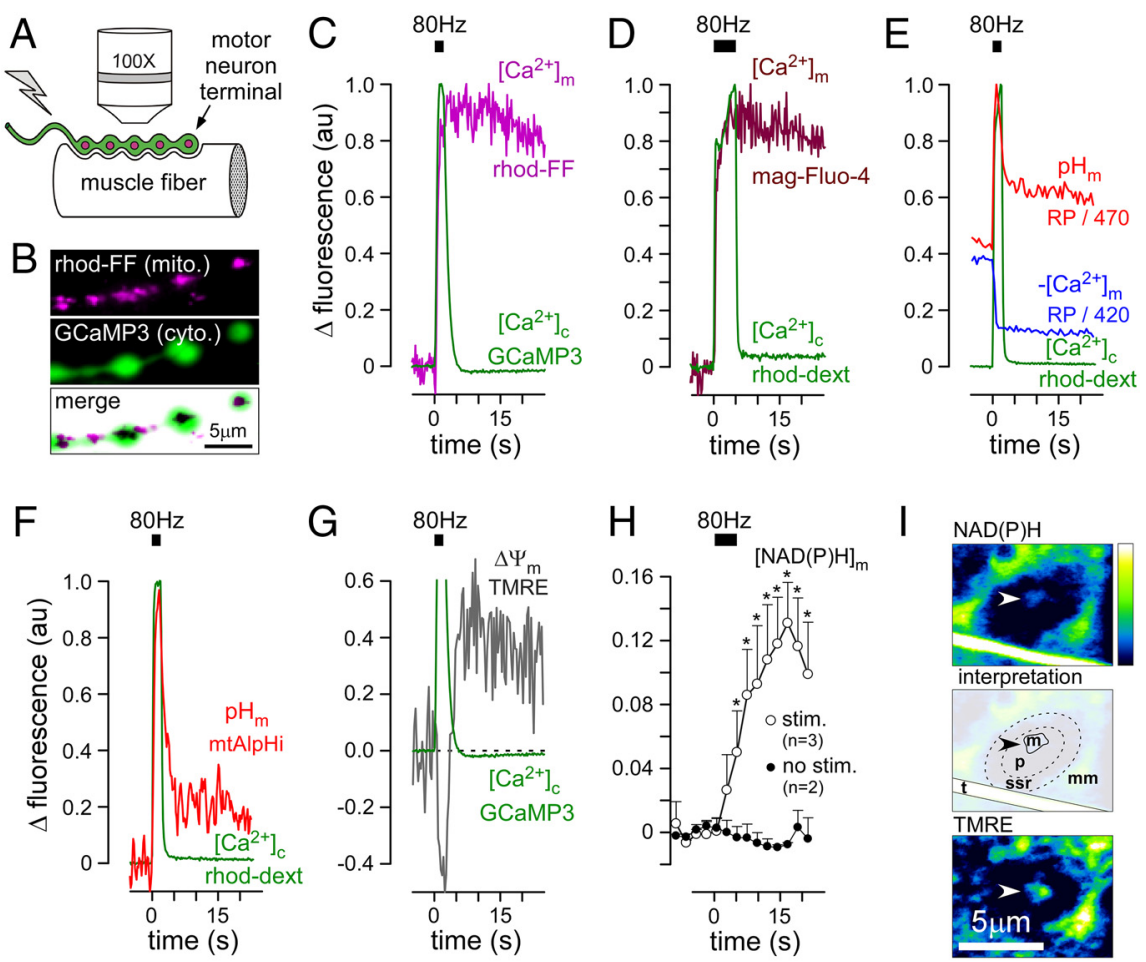

Figure 1. Presynaptic mitochondrial matrix $\mathrm{pH}\left(\mathrm{pH}_{\mathrm{m}}\right)$, inner mitochondrial membrane potential $\left(\Delta \psi_{\mathrm{m}}\right)$, and mitochondria H levels ( $[\mathrm{NAD}(\mathrm{P}) \mathrm{H}]_{\mathrm{m}}$ ) increase in response to nerve stimulation. $\boldsymbol{A}$, Schematic of a motor neuron terminal examined in situ. loaded with rhod-FF in type-lb terminal boutons on muscle 13 containing the cytosolic (cyto.) Ca ${ }^{2+}$-reporter GCaMP3. C, A nerve reported by GCaMP3 and rhod-FF, respectively). $\boldsymbol{D}$, Longer nerve stimulus trains $(5 \mathrm{~s})$ evoked changes in $\left[\mathrm{Ca}^{2+}\right]_{\mathrm{c}}$ and $\left[\mathrm{Ca}^{2+}\right]_{\mathrm{m}}$ (reported by rhod-dextran and mag-Fluo- 4 respectively) with similar kinetics to those evoked by $2 \mathrm{~s}$ trains. $\boldsymbol{E}-\boldsymbol{G}$, Nerve stimulus fluorescence are normalized to a range of $1 \mathrm{U}$ (arbitrary units), except for mito-RP where peak $470 \mathrm{~nm}$ excitation fluorescence $\left(\mathrm{RP} / 470: \mathrm{pH}_{\mathrm{m}}\right)$ is normalized to 1 and the $420 \mathrm{~nm}$ excitation fluorescence $\left(\mathrm{RP} / 420:-\left[\mathrm{Ca}^{2+}\right]_{\mathrm{m}}\right)$ is scaled in proportion, as the trace is thus labeled $-\left[\mathrm{Ca}^{2+}\right]_{\mathrm{m}}$. In each panel $(\mathbf{C}-\mathbf{G})$, the data come from a single terminal in separate larvae, and representative traces are shown with no bleaching correction and no data averaging. $\boldsymbol{H}$, Nerve stimulation $(5 \mathrm{~s})$ produces changes in $\operatorname{NAD}(\mathrm{P}) \mathrm{H}$ . Pooled data are presented as mean \pm SEM; $n$, number of different termini. Asterisks indicate significant differences $(p<$ mitochondria (mm), and the branch of a tracheole (t). Bottom, TMRE fluorescence image from the same field of view as in the top mage, subsequent to NAD(P)H imaging. Scale bar, $5 \mu \mathrm{m}$. NAD(P)H and TMRE imaging were not conducted simultaneously due to indicated, larvae were $w^{1118}$ wild type. 0ther genotypes were: GCaMP3: w-; OK6-GAL4/UAS-GCaMP3.0; + /+, mito-RP: w- ; OK6-GAL4/UAS-mito-RP(\#8); +/+, and, mtAlpHi: w-;0K6-GAL4/UAS-mtAlpHi(\#2); +/+. All experiments were performed on MN13lb termini in $2 \mathrm{~mm} \mathrm{Ca}^{2+}$ physiological saline (HL6), with $7 \mathrm{~mm} \mathrm{L-glutamic} \mathrm{acid.}$

ATP consumption rate is depressed to a level where changes in the ADP:ATP ratio are insufficient to stimulate mitochondrial metabolism. We tested for a primary effect of the ADP:ATP ratio by applying bongkrekic acid to inhibit the adenine nucleotide transporter. Bongkrekic acid should reduce the availability of ADP to the $\mathrm{F}_{1} \mathrm{~F}_{0}$-ATPase and thereby diminish the capacity of a rapid increase in the cytosolic ADP:ATP ratio to stimulate respiration (Henderson and Lardy, 1970; Klingenberg, 2008). Bongkrekic acid appeared to depress basal $\mathrm{pH}_{\mathrm{m}}$ levels but did not diminish nerve stimulus-evoked changes in $\mathrm{pH}_{\mathrm{m}}$ (Fig. 2C, fourth section, and $D$ ).Together, these data provide strong support for the hypothesis that mitochondrial $\mathrm{Ca}^{2+}$ uptake, rather than a change in the ADP:ATP ratio, plays a primary role in stimulating 

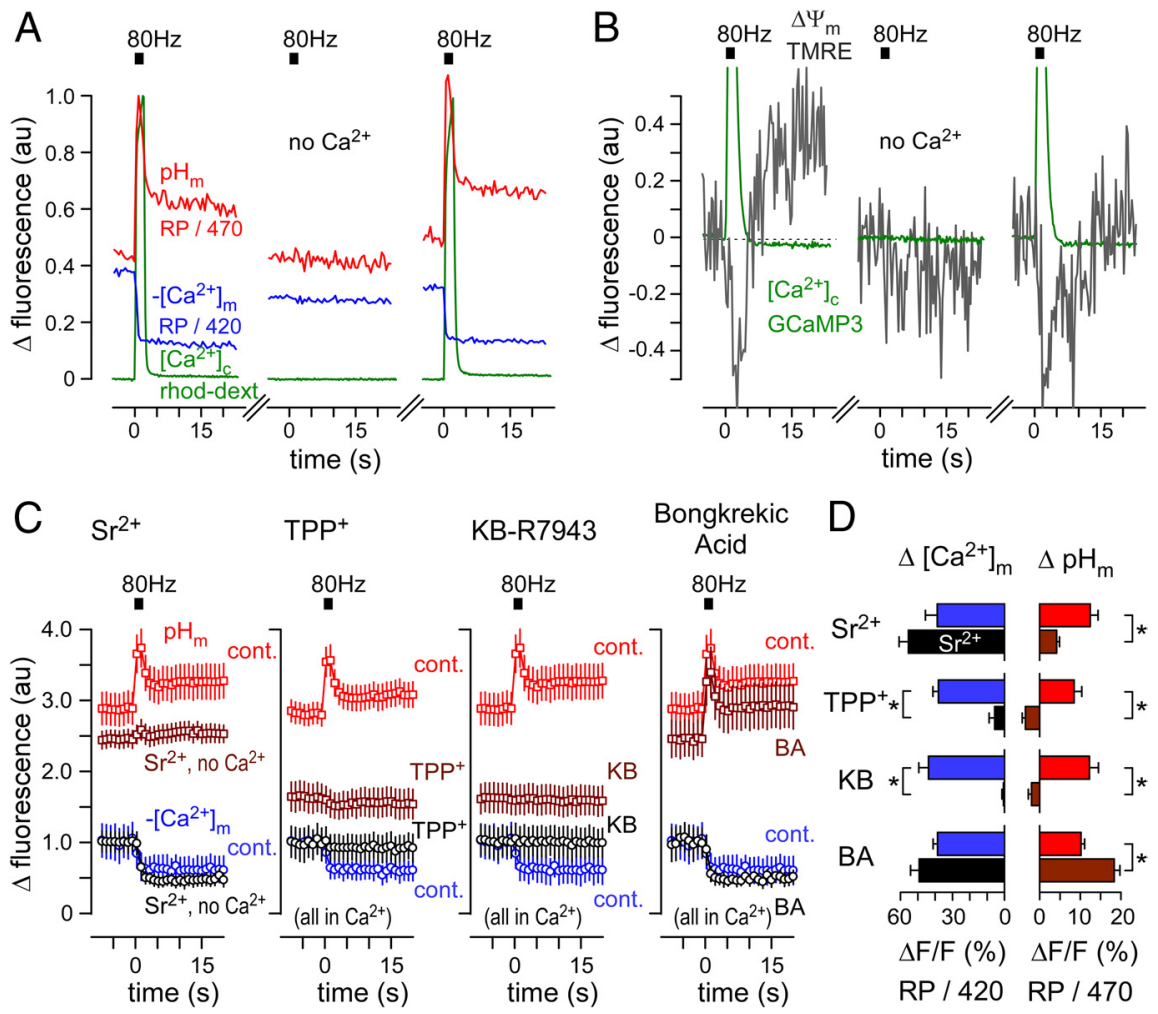

Figure 2. The increase in mitochondrial energy metabolism associated with nerve activity is $\mathrm{Ca}^{2+}$ dependent. $A$, Stimulation (bar: $80 \mathrm{~Hz}, 2 \mathrm{~s}$ ) evoked changes in $\left[\mathrm{Ca}^{2+}\right]_{\mathrm{C}}\left[\mathrm{Ca}^{2+}\right]_{\mathrm{m}}$, and pH $\mathrm{m}$. All stimulus-evoked fluorescent transients are abolished when $\mathrm{Ca}^{2+}$ is omitted from HL6 and $2 \mathrm{~mm}$ EGTA is present. Responses recover when $\mathrm{Ca}^{2+}$ is readministered. $\boldsymbol{B}$, Stimulation as in $\boldsymbol{A}$ produced changes in $\left[\mathrm{Ca}^{2+}\right]_{\mathrm{C}}$ and $\Delta \psi_{\mathrm{m}}$, and changes in $\Delta \psi_{\mathrm{m}}$ are $\mathrm{Ca}^{2+}$ dependent. Responses in $\boldsymbol{A}$ and $\boldsymbol{B}$ return when preparations are again superfused with $2 \mathrm{~mm} \mathrm{Ca}{ }^{2+} H L 6$. Fluorescent reporters are identified on each plot in $\boldsymbol{A}$ and $\boldsymbol{B}$. In each panel $(\boldsymbol{A}$ and $B$ ) the data come from a single terminal. Changes in fluorescence were scaled as described in Figure 1 with no bleaching correction and no data averaging. C, Average mito-RP responses to an $80 \mathrm{~Hz} 2$ s nerve stimulus during different treatments (brown and black traces); first section: $4 \mathrm{~mm} \mathrm{Sr}^{2+}, 2 \mathrm{~mm}$ EGTA, no added $\mathrm{Ca}^{2+}$; second section: $100 \mu \mathrm{m} \mathrm{TPP}{ }^{+}$and $2 \mathrm{~mm} \mathrm{Ca}^{2+}$; third section: $100 \mu \mathrm{m}$ KB-R7943 and $2 \mathrm{~mm} \mathrm{Ca}^{2+}$; fourth section: $50 \mu \mathrm{m}$ bongkrekic acid and $2 \mathrm{~mm} \mathrm{Ca}^{2+}$. Control (cont.) data are also shown in each panel $\left(2 \mathrm{~mm} \mathrm{Ca}^{2+}\right.$; red and blue traces). Data (frame) acquisition rate was $2 \mathrm{~Hz}$ per mito-RP excitation wavelength. Data are presented as mean \pm SEM, and scaled to the mito-RP $420 \mathrm{~nm}$ excitation trace before stimulation; $N \geq 4$ (larvae). TPP ${ }^{+}, \mathrm{KB}-\mathrm{R} 7943$, and bongkrekic acid were applied for $10 \mathrm{~min}$ in $\leq 1 \%$ DMSO. $D$, A quantitative summary of the data in $C$, where $\Delta\left[\mathrm{Ca}^{2+}\right]_{\mathrm{m}}$ and $\Delta \mathrm{pH}_{\mathrm{m}}$ represent the average change in $\left[\mathrm{Ca}^{2+}\right]_{\mathrm{m}}$ and $\mathrm{pH}_{\mathrm{m}}$ (between time $=-1$ and $10 \mathrm{~s}$ ) reported by mito-RP when using excitation wavelengths of 420 and $470 \mathrm{~nm}$, respectively. Asterisks indicate significant differences from controls $(p<0.01)$ in one-way ANOVAs applied separately to $\left[\mathrm{Ca}^{2+}\right]_{\mathrm{m}}$ data and $\mathrm{pH}_{\mathrm{m}}$ data $(p<0.05$ overall, Holm-Sidak posthoc tests). Genotypes are as follows: A: mito-RP: w-;0K6-GAL4/UAS-mito-RP(\#8); $+/+; \boldsymbol{B}$ : GCaMP3: w-;0K6-GAL4/UAS-GCaMP3.0; $+/+;$ Cand $\boldsymbol{D}:$ w $-;$ OK6GAL4/OK6-GAL4; UAS-mito-RP(\#9)/+. All experiments were performed on MN13lb termini in HL6 saline with 7 mm L-glutamic acid. Except where indicated otherwise, $2 \mathrm{~mm} \mathrm{Ca}^{2+}$ was present.

rapid increases in mitochondrial energy metabolism in these nerve termini.

\section{Identified motor neurons have stereotypical firing rates in situ}

Changes in the mitochondrial energy metabolism studied in the experiments above were evoked by impulse trains delivered at 80 $\mathrm{Hz}$. To determine how this frequency fits within the range of frequencies that occur in situ, we placed intracellular micropipettes in adjacent body wall muscle fibers to record synaptic activity while the central pattern generator drove patterned activity in the MNs (Fig. $3 A$ ), an experimental condition referred to as fictive locomotion. The innervation of muscles 7, 6, 13, 12, and 4 is highly stereotypical (Hoang and Chiba, 2001), and MNs contributing EJPs were identified using a previously described method (Chouhan et al., 2010). EJPs arising from axons that form type Is boutons on many muscle fibers were identified and dismissed from further consideration based on their synchronicity and large ampli- tude in commonly innervated muscle fibers. The intervals between contiguous EJPs were used to calculate instantaneous firing frequencies for each $\mathrm{MN}$ that formed type Ib boutons. The average of these frequencies was calculated over a period of $2 \mathrm{~s}$ during the MN's most intense activity (Fig. 3B,C). We refer to this value as the MN's native firing frequency. Each MN displayed a characteristic native firing frequency that differed significantly from the firing frequency of other MNs (Fig. 3 B, C) (Fig. 3C; MN6/7Ib, $21.3 \mathrm{~Hz}$; MN13Ib, $42.0 \mathrm{~Hz}$; MN12Ib, $32.4 \mathrm{~Hz}$; MN4Ib, $24.2 \mathrm{~Hz}$ ). Clearly, these endogenous frequencies are below the $80 \mathrm{~Hz}$ stimulus frequency used to stimulate mitochondrial $\mathrm{Ca}^{2+}$ uptake and energy metabolism in Figures 1 and 2. Thus, the question arises, are the mitochondrial phenomena observed at $80 \mathrm{~Hz}$ also seen at lower frequencies?

\section{Presynaptic mitochondria take up $\mathrm{Ca}^{2+}$ at stimulus frequencies close to the native firing frequency of their motor neuron}

To determine whether mitochondria take up $\mathrm{Ca}^{2+}$ at firing frequencies close to endogenous rates, we measured changes in mito-RP fluorescence evoked by $2 \mathrm{~s}$ stimulus trains of different frequencies. The lowaffinity $\mathrm{Ca}^{2+}$-reporter rhod-dextran shows that the concentration of cytosolic $\mathrm{Ca}^{2+}$ $\left(\left[\mathrm{Ca}^{2+}\right]_{\mathrm{c}}\right)$ increases in proportion to stimulus frequency over a range of frequencies up to $80 \mathrm{~Hz}$ (Fig. 4A; Macleod et al., 2002; Chouhan et al., 2010; Hendel et al., 2008; He and Lnenicka, 2011). Changes in the level of mito-RP fluorescence were measured $10 \mathrm{~s}$ after the start of the stimulus train (Fig. $4 \mathrm{~A}$, far right sections). Average mito-RP responses $\left[420 \mathrm{~nm}\right.$ excitation $\left.\left(\left[\mathrm{Ca}^{2+}\right]_{\mathrm{m}}\right)\right]$ were normalized to a maximum response at $120 \mathrm{~Hz}$ stimulation (fluorescence responses did not increase beyond $120 \mathrm{~Hz}$ stimulation), and data were fit with four parameter logistic functions (Fig. $4 B$ ). These data were used to calculate an $\mathrm{EC}_{50}$ for each $\mathrm{MN}$ that represents the stimulus frequency producing a $50 \%$ maximal mito-RP response under $420 \mathrm{~nm}$ excitation (mito- $\mathrm{RP}_{50}$ ). A plot of mito- $\mathrm{RP}_{50}$ frequencies versus native firing frequencies showed a significant correlation (Fig. 4C), although the relationship diverges from a strict one-to-one mapping (dotted line). The mito- $\mathrm{RP}_{50}$ frequencies are significantly different between MN6/7Ib, MN12Ib, and MN13Ib, as shown. Because all points fall below the dotted line, this indicates that all MNs fire at a rate that will produce at least a 50\% maximal mito-RP response within $2 \mathrm{~s}$.

To graphically represent mitochondrial $\mathrm{Ca}^{2+}$ uptake within a physiological context, the data in Figure $4 B$ were replotted after dividing the frequency at which each MN was stimulated by its native firing frequency (Fig. $4 D$; closed symbols). The resulting curves demonstrate that presynaptic mitochondria rapidly accumulate $\mathrm{Ca}^{2+}$ once $\mathrm{MN}$ firing exceeds approximately half of its native firing frequency. As the curves of the faster firing MNs are 


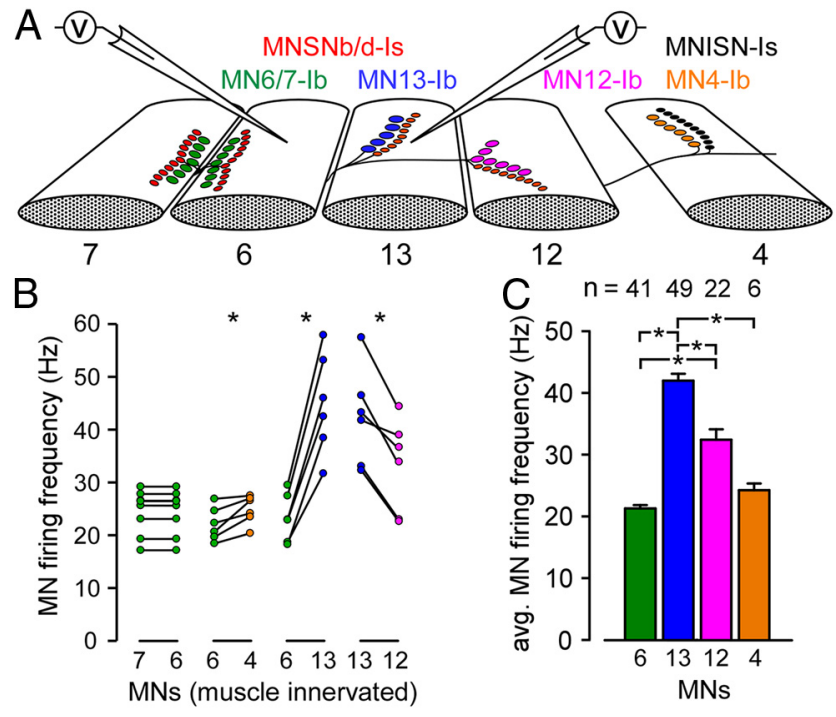

Figure 3. Individually identified motor neurons have a characteristic firing rate in situ. $\boldsymbol{A}$, Schematic of larval body wall muscles and dual intracellular recording micropipettes. $\boldsymbol{B}$, Average (avg.) instantaneous firing frequencies for each $\mathrm{MN}$, calculated as the reciprocal of the interval between EJPs averaged over a $2 \mathrm{~s}$ period of the MN's most intense activity. The data represent paired recordings. MNs were identified according to the muscle they exclusively innervate. Asterisks indicate significant differences between MNs when the means are tested ( $p<0.005$, paired Student's $t$ tests). Recordings were in $0.4 \mathrm{~mm} \mathrm{Ca}^{2+} \mathrm{HL} 6$. C, The average firing frequency for each MN calculated from pooled measurements with $\mathrm{Ca}^{2+}$ present at 0.4 , 0.8 or $2.0 \mathrm{~mm}$. Firing rates are not dependent on $\mathrm{Ca}^{2+}$ levels in the saline in the range between 0.4 and $2 \mathrm{~mm}$ (data not shown). $n$ indicates the number of recordings. Larvae were $w^{1118}$ wild type. Asterisks indicate significant differences between MNs $(p<0.05$, Kruskall-Wallis oneway ANOVA on ranks with Dunn's correction).

higher in the transformed plot (Fig. 4D; MN13Ib versus MN6/ 7Ib), they may be more active at using the mechanism of $\mathrm{Ca}^{2+}$ stimulated oxidative phosphorylation to support their activity. To determine whether the relatively high $\mathrm{Ca}^{2+}$ affinity of mito-RP was somehow responsible for the trend observed in Figure $4 D$, mitochondria in the fastest (MN13Ib) and slowest (MN6/7Ib) firing MNs were loaded with the low-affinity $\mathrm{Ca}^{2+}$ indicator rhod-FF, and the MNs were stimulated at their native firing frequencies. The lower estimates derived from the rhod-FF data suggest that mito-RP saturates at higher stimulation frequencies in both MNs (Fig. 4D; open symbols). However, in agreement with the mito-RP data, the rhod-FF data show a significant difference between MNs, indicating that mitochondria in the fastest firing $\mathrm{MN}$ take up a greater relative load of $\mathrm{Ca}^{2+}$ than the slowest firing $\mathrm{MN}$ when $\mathrm{MNs}$ fire at their native frequencies.

\section{$\mathrm{pH}_{\mathrm{m}}$ shows a similar dependence on $\left[\mathrm{Ca}^{2+}\right]_{\mathrm{m}}$ in different MNs}

To determine whether mitochondrial $\mathrm{Ca}^{2+}$ uptake has a similar influence on mitochondrial metabolism in different MNs, average mito-RP responses representing changes in $\mathrm{pH}_{\mathrm{m}}(490 \mathrm{~nm}$ excitation) were plotted against responses representing changes in $\left[\mathrm{Ca}^{2+}\right]_{\mathrm{m}}$ (420 nm excitation) (Fig. 4E). Changes in $\left[\mathrm{Ca}^{2+}\right]_{\mathrm{m}}$ did not give rise to any measureable change in $\mathrm{pH}_{\mathrm{m}}$ until $\left[\mathrm{Ca}^{2+}\right]_{\mathrm{m}}$ changed significantly, i,e, until the $420 \mathrm{~nm}$ mito-RP response exceeded $\sim 20 \%$. Beyond this threshold, $\mathrm{pH}_{\mathrm{m}}$ appears to be highly responsive to changes in $\left[\mathrm{Ca}^{2+}\right]_{\mathrm{m}}$ in all MNs.
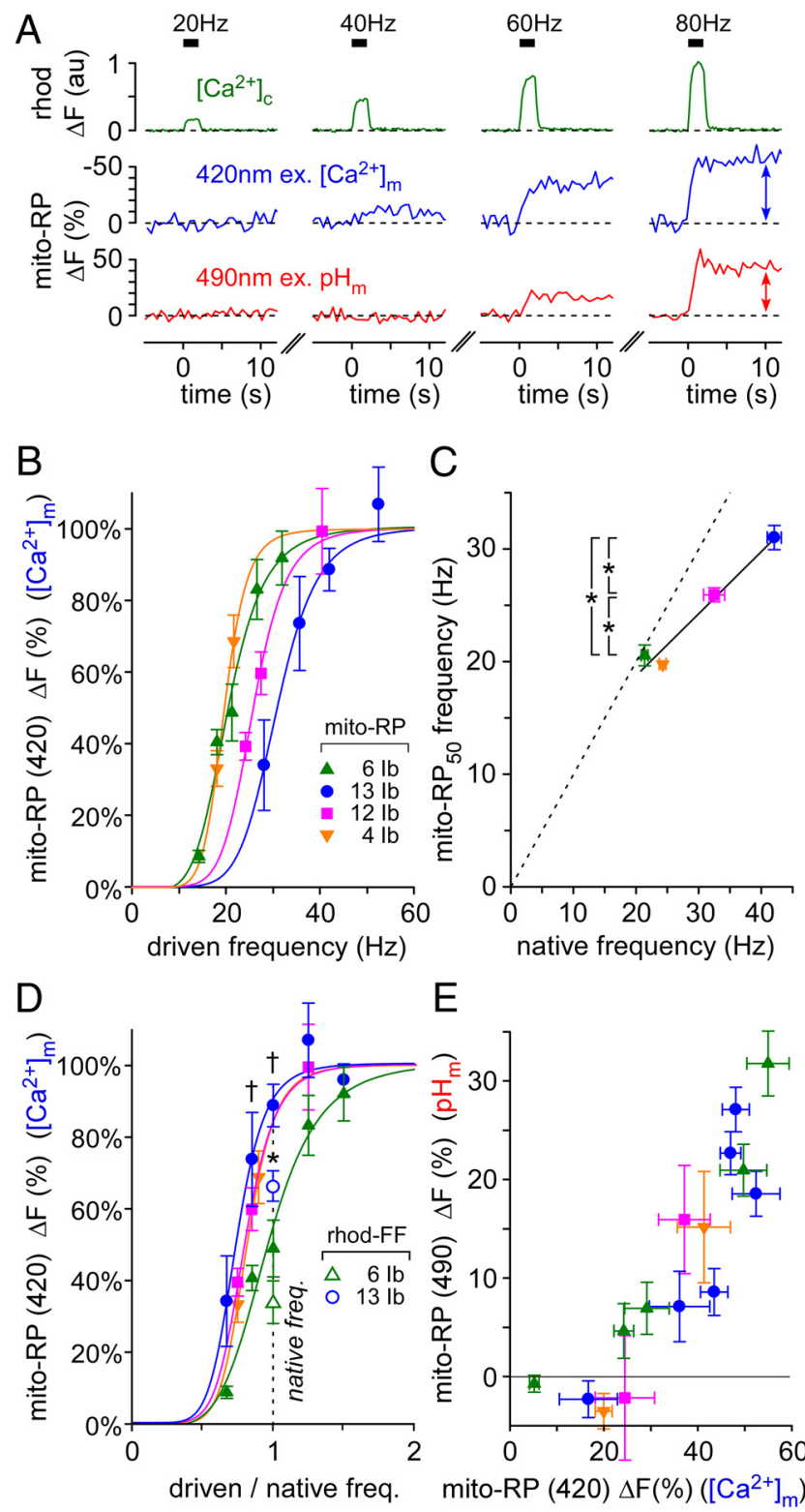

Figure 4. Presynaptic mitochondria take up $\mathrm{Ca}^{2+}$ close to the native firing frequency of their motor neuron. $\boldsymbol{A}$, Changes in $\left[\mathrm{Ca}^{2+}\right]_{\mathrm{c}}$ (rhod-dextran) in a MN13lb terminal in response to individual nerve stimulus trains $2 \mathrm{~s}$ in duration (trains separated by $10 \mathrm{~min}$ ). Changes in $\left[\mathrm{Ca}^{2+}\right]_{\mathrm{m}}$ and pH (mito-RP, 420 and $490 \mathrm{~nm}$ excitation, respectively) evoked by the same stimulus protocol. Rhod fluorescence and mito-RP fluorescence ( 420 and $490 \mathrm{~nm}$ excitation) were normalized to a resting level (prestimulus) value of 0 . No data averaging or smoothing. $\boldsymbol{B}$, Normalized average changes in mito-RP fluorescence ( $420 \mathrm{~nm}$ ex.) across MN termini for different nerve stimulus frequencies (driven frequency). An ANOVA was not applied as values on the abscissa were different between all MNs. C, Stimulus frequencies producing a 50\% maximal mito-RP response (mito- $\mathrm{RP}_{50}$ ) in each $\mathrm{MN}$ were plotted against the native firing frequency of each MN. The values were correlated ( $p=0.018, r=$ 0.982 , Pearson's Product Moment), and mito-RP ${ }_{50}$ frequencies were significantly different $(p<$ 0.001 ) between MN6/7lb, MN12lb, and MN13lb, as indicated with asterisks (one-way ANOVA, $p<$ 0.05 overall, Holm-Sidakposthoctests). $\boldsymbol{D}$, Normalized average changes in mito-RP fluorescence ( 420 $\mathrm{nm}$ excitation) plotted against the stimulus frequency relative to the $\mathrm{MN}^{\prime}$ 's native firing frequency (closed symbols). Significant differences $(p<0.01$ ) were found between MN13lb and MN6/7lb, as indicated with daggers (two-way ANOVA, $p<0.05$ overall, Tukey posthoctests). The relative rhod-FF fluorescence responses were also plotted for MN6/7lb and MNI3lb presynaptic mitochondria (open symbols; native firing frequency/120 Hz). These values were significantly different (asterisk; $p<$ 0.001, two-tailed Student's $t$ test; MN13lb: 67.1\%; MN6/7lb: 32.7\%) $\boldsymbol{E}$, Average changes in $\mathrm{pH}_{\mathrm{m}}$ plotted against average changes in $\left[\mathrm{Ca}^{2+}\right]_{\mathrm{m}}$ in each $\mathrm{MN}$ (before normalization). The legend shown in $\boldsymbol{B}$ is used for $\boldsymbol{B}-\boldsymbol{E}$. Pooled data are presented as mean \pm SEM; $n \geq 5$. Larval genotypes: $\boldsymbol{w}-$; OK6-GAL4/UAS-mito-RP(\#8); UAS-DsRed/+, except for $w^{1118}$ wild type used when loading rhod-FF. All experiments were in $2 \mathrm{~mm} \mathrm{Ca}^{2+} \mathrm{HL} 6$ saline with $7 \mathrm{~mm} \mathrm{~L}$-glutamic acid. 


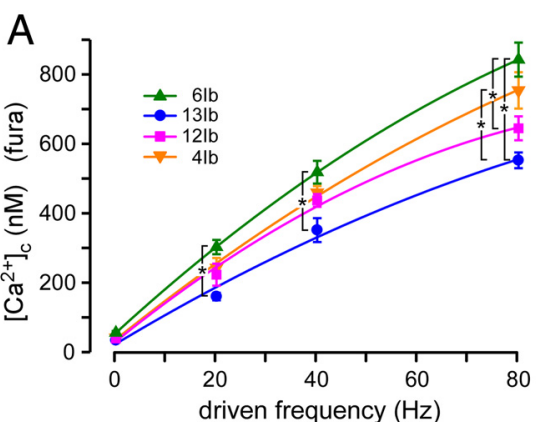

C

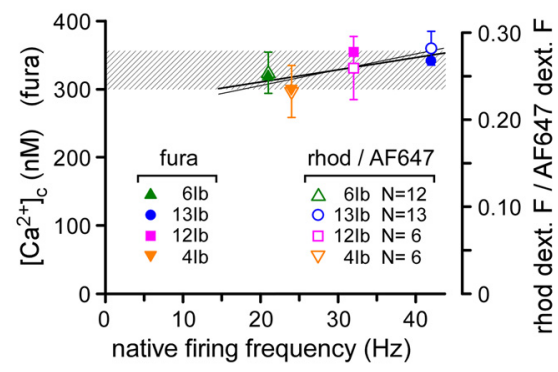

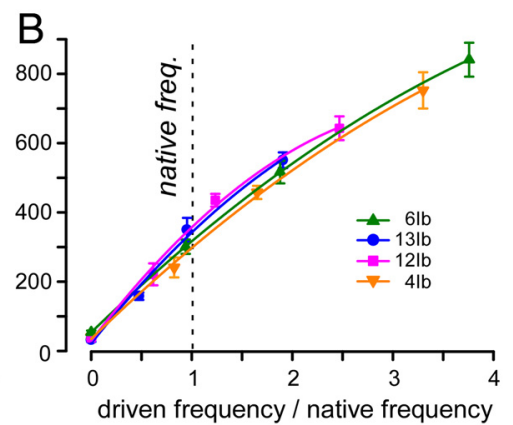

D

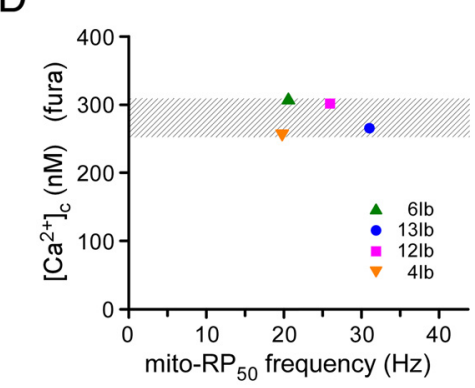

Figure 5. Presynaptic $\mathrm{Ca}^{2+}$ levels $\left(\left[\mathrm{Ca}^{2+}\right]_{c}\right)$ are similar in different motor neurons when each is driven at its native firing frequency. $A$, Average $\left[\mathrm{Ca}^{2+}\right]_{C}$ in identified MN termini during $2 \mathrm{~s}$ nerve stimulus trains at the driven frequency shown. Asterisks indicate significant differences ( $p<0.01$ ) between MNs (two-way ANOVA, $p<0.05$ overall, Tukey post hoc test). $\boldsymbol{B}$, Average $\left[\mathrm{Ca}^{2+}\right]_{c}$ plotted against stimulus frequency relative to the $\mathrm{MN}^{\prime}$ s native firing frequency. $C,\left[\mathrm{Ca}^{2+}\right]_{\mathrm{c}}$ values for each $\mathrm{MN}$ at its native firing frequency, obtained by projecting the native firing frequency of each MN (Fig. 3C) onto the ordinate in $\boldsymbol{A}$ (closed symbols; left ordinate). Independent estimates of relative $\left[\mathrm{Ca}^{2+}\right]_{\mathrm{c}}$ values were obtained by loading MN termini at a fixed ratio of rhod-dextran to AF647 dextran and stimulating each MN at its native firing frequency (open symbols; right ordinate). Linear regression analysis failed to find significant associations in either the fura or rhod-dextran datasets $(r=0.84, F=4.7, p=0.16$, and $r=0.69, F=$ $1.9, p=0.31$, respectively). $\boldsymbol{D},\left[\mathrm{Ca}^{2+}\right]_{c}$ values for each $\mathrm{MN}$ at its mito- $\mathrm{RP}_{50}$ frequency [representing the apparent affinity of mitochondria for $\mathrm{Ca}^{2+}\left(K_{\text {app }}\right)$ ], obtained by projecting the mito-RP ${ }_{50}$ frequency of each MN (Fig. 4C) onto the ordinate in $A$. Pooled data are presented as mean $\pm \mathrm{SEM} ; n \geq 6$. Larvae were $w^{1118}$ wild type. All experiments were performed in $2 \mathrm{~mm} \mathrm{Ca}{ }^{2+} \mathrm{HL}$ saline with 7 mm L-glutamic acid.

\section{Native firing frequency $\left[\mathrm{Ca}^{2+}\right]_{\mathrm{c}}$ values are similar in different motor neurons}

Mitochondrial $\mathrm{Ca}^{2+}$ uptake varies across $\mathrm{MNs}$ for any given nerve stimulus frequency (Fig. $4 B$ ). One explanation for this may be that presynaptic $\left[\mathrm{Ca}^{2+}\right]_{\mathrm{c}}$ achieves a different level in each $\mathrm{MN}$. An alternative explanation would be that mitochondria in different MNs have different affinities for $\mathrm{Ca}^{2+}$. To determine $\left[\mathrm{Ca}^{2+}\right]_{\mathrm{c}}$ during nerve activity and thereby investigate the first hypothesis, we loaded $\mathrm{MN}$ termini with the $\mathrm{Ca}^{2+}$ reporter fura-dextran and found that $\left[\mathrm{Ca}^{2+}\right]_{\mathrm{c}}$ values at any given stimulus frequency were significantly different across MNs (Fig. 5A). The MN termini that achieved the highest $\left[\mathrm{Ca}^{2+}\right]_{\mathrm{c}}$ levels contained mitochondria that were the most responsive to nerve stimulation, e.g., MN6/7Ib. Thus, the trend in $\left[\mathrm{Ca}^{2+}\right]_{\mathrm{c}}$ levels (Fig. $5 A$ ) provides an explanation for the differences in mitochondrial uptake across MNs shown in Figure $4 B$.

The physiological implications of these data became evident when they were replotted after dividing the frequency at which each $\mathrm{MN}$ was stimulated by its native firing frequency (Fig. $5 B$ ). Then, for all MNs, $\left[\mathrm{Ca}^{2+}\right]_{\mathrm{c}}$ values were similar across their relative firing frequency range. When native firing frequency $\left[\mathrm{Ca}^{2+}\right]_{\mathrm{c}}$ was plotted for each MN (Fig. 5C), it was clear that MNs operated in a similar $\left[\mathrm{Ca}^{2+}\right]_{\mathrm{C}}$ range during endogenous activity (filled symbols, $329 \pm 11$ $\mathrm{nM})$. However, as $\left[\mathrm{Ca}^{2+}\right]_{\mathrm{c}}$ values in this plot derive from native firing frequency values (Fig. $3 C$ ) extrapolated onto the ordinate in Figure $5 A$, they do not provide for a strong test for differences between $\left[\mathrm{Ca}^{2+}\right]_{\mathrm{c}}$ values. This shortcoming was remedied by filling MNs with a mixture of rhod-dextran and AF647-dextran and stimulating each $\mathrm{MN}$ at its native firing frequency. Rhod-dextran has a larger dynamic range and a lower affinity than fura-dextran (3 $\mu \mathrm{M}$ vs $594 \mathrm{nM}$ ). Rhoddextran was unable to resolve a significant difference in $\left[\mathrm{Ca}^{2+}\right]_{\mathrm{c}}$ between $\mathrm{MN}$ termini at their native firing frequencies (open symbols; $F=0.62$, one-way ANOVA). A trend indicating that $\left[\mathrm{Ca}^{2+}\right]_{\mathrm{c}}$ was slightly higher in the faster firing neurons was observed in the $\left[\mathrm{Ca}^{2+}\right]_{c}$ estimates derived from rhod-dextran and from fura-dextran, but in neither case was the association significant. If $\left[\mathrm{Ca}^{2+}\right]_{\mathrm{m}}$ has a second power dependence on $\left[\mathrm{Ca}^{2+}\right]_{\mathrm{c}}$ (Nicholls and Ferguson, 2002), then a small but difficult to resolve trend in $\left[\mathrm{Ca}^{2+}\right]_{\mathrm{c}}$ may be sufficient to explain the trend in $\left[\mathrm{Ca}^{2+}\right]_{\mathrm{m}}$. A comparison between Figure $4 B$ and Figure $5 A$ indicates that $\left[\mathrm{Ca}^{2+}\right]_{\mathrm{m}}$ levels are indeed very sensitive to changes in $\left[\mathrm{Ca}^{2+}\right]_{\mathrm{c}}$ near the native firing frequency.

\section{Presynaptic mitochondria in different motor neurons show similar affinities for $\mathrm{Ca}^{2+}$ uptake}

An explanation for the differences in mitochondrial $\mathrm{Ca}^{2+}$ uptake between $\mathrm{MNs}$ at any given stimulus frequency (Fig. $4 B$ ), can be found in the differences in $\left[\mathrm{Ca}^{2+}\right]_{c}$ values between MNs (Fig. 5A). However, it is more difficult to explain the differences in mitochondrial $\mathrm{Ca}^{2+}$ uptake between MNs at their native firing frequencies (Fig. $4 D$ ), as we were unable to resolve a difference in $\left[\mathrm{Ca}^{2+}\right]_{c}$ between $\mathrm{MNs}$ at their native firing frequencies (Fig. $5 C$ ). An explanation might be found if the apparent mitochondrial $\mathrm{Ca}^{2+}$ affinity $\left(K_{\text {app }}\right)$ is different in different MNs. To estimate $K_{\text {app }}$ for each MN, its mito- $\mathrm{RP}_{50}$ frequency (Fig. 4C) was projected from the abscissa to the ordinate of Figure $5 A . K_{\text {app }}$ values fell in a range between 253 and $307 \mathrm{~nm}$ (Fig. 5D; $281 \pm 13 \mathrm{nM}$ ). There was no indication of higher $K_{\text {app }}$ values in faster firing MNs, in which case differences in $K_{\text {app }}$ values between MNs could not explain differences in mitochondrial uptake across $\mathrm{MNs}$ at their native firing frequencies. Therefore, we favor the explanation that the nonsignificant trend in $\left[\mathrm{Ca}^{2+}\right]_{\mathrm{c}}$ observed in Figure $5 C$ does in fact represent small differences between MNs.

\section{Presynaptic mitochondria avidly acquire $\mathrm{Ca}^{2+}$ during endogenous nerve activity}

Presynaptic mitochondria acquire $\mathrm{Ca}^{2+}$ when axon firing is driven by externally applied stimuli, but stimulus trains are unlikely to adequately recapitulate complex endogenous activity. To test whether endogenous activity does lead to $\mathrm{Ca}^{2+}$ acquisition by presynaptic mitochondria, we left the motor nerves intact and examined changes in $\left[\mathrm{Ca}^{2+}\right]_{\mathrm{c}}$ and $\left[\mathrm{Ca}^{2+}\right]_{\mathrm{m}}$ in dissected restrained larvae during fictive locomotion (Fig. 6A). Endogenous activity led to robust changes in $\left[\mathrm{Ca}^{2+}\right]_{\mathrm{c}}$ (revealed by cytosolic GCaMP3 fluorescence) that reflected the motor pattern (Fig. $6 B, C)$. It also led to increases in $\left[\mathrm{Ca}^{2+}\right]_{\mathrm{m}}$ (revealed by mitochon- 

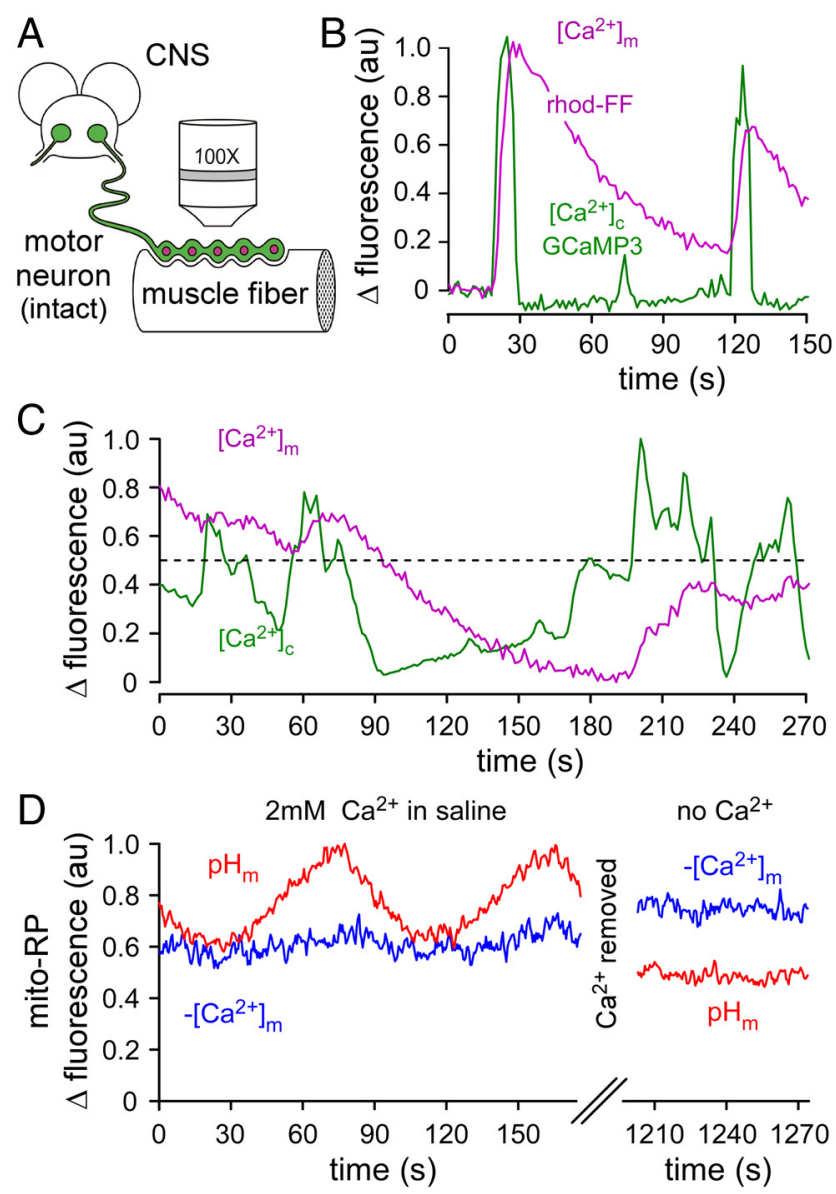

Figure 6. Mitochondrial $\mathrm{pH}\left(\mathrm{pH}_{\mathrm{m}}\right)$ is responsive to the changes in $\left[\mathrm{Ca}^{2+}\right]_{\mathrm{m}}$ that occur during endogenous nerve activity. $\boldsymbol{A}$, Schematic of a motor neuron terminal examined in situ, with an intact axon extending from the soma in the CNS. B, C, Changes in $\left[\mathrm{Ca}^{2+}\right]_{\mathrm{C}}(\mathrm{GCaMP3})$ and $\left[\mathrm{Ca}^{2+}\right]_{\mathrm{m}}$ (rhod-FF) during fictive locomotion. The dotted line in $C$ indicates the approximate GCaMP3 fluorescence threshold for mitochondrial $\mathrm{Ca}^{2+}$ uptake. $\boldsymbol{D}$, Changes in $\left[\mathrm{Ca}^{2+}\right]_{\mathrm{m}}$ and $\mathrm{pH}_{\mathrm{m}}$ (mito-RP) during fictive locomotion, before (left) and after (right) the preparation is rinsed with $\mathrm{HL} 6$ containing $2 \mathrm{~mm}$ EGTA and no added $\mathrm{Ca}^{2+}$. Changes in fluorescence in $\boldsymbol{D}$ were scaled as described in Figure 1. Data were corrected for bleaching in $\boldsymbol{B}$ and $\boldsymbol{C}$, but not in $\boldsymbol{D}$. Genotypes are as follows. $\boldsymbol{B}$ : GCaMP3: w -; OK6-GAL4/UAS-GCaMP3.0; +/+;C, D: mito-RP: w-;0K6GAL4/UAS-mito-RP(\#8); + / + Experiments in $\boldsymbol{B}$ - $\boldsymbol{D}$ were performed on MN13lb termini in HL6 saline with $7 \mathrm{~mm} \mathrm{L-glutamic} \mathrm{acid.} \mathrm{Except} \mathrm{where} \mathrm{indicated} \mathrm{otherwise,} 2 \mathrm{~mm} \mathrm{Ca}^{2+}$ was present.

drial rhod-FF fluorescence) that matched the onset of $\left[\mathrm{Ca}^{2+}\right]_{\mathrm{c}}$ transients. This demonstrates a robust mitochondrial capacity to acquire $\mathrm{Ca}^{2+}$ during endogenous activity.

$\left[\mathrm{Ca}^{2+}\right]_{\mathrm{m}}$ and $\mathrm{pH}_{\mathrm{m}}$ are elevated during fictive locomotion

Studies of Drosophila larval locomotion indicate that the MN bursts may repeat as often as once every second during the rapid peristalsis of locomotion (Klose et al., 2005). Thus, since $\left[\mathrm{Ca}^{2+}\right]_{c}$ transients are closely spaced and mitochondrial $\mathrm{Ca}^{2+}$ release follows a slow time course, there will be occasions where $\left[\mathrm{Ca}^{2+}\right]_{\mathrm{m}}$ summates substantially (Fig. 6C). Mito-RP fluorescence in intact MNs shows that $\mathrm{pH}_{\mathrm{m}}$ is high whenever $\left[\mathrm{Ca}^{2+}\right]_{\mathrm{m}}$ is high (Fig. $6 \mathrm{D}$, compare left and right sections). This presumably reflects ongoing motor patterns, but there are no genetically encoded $\mathrm{Ca}^{2+}$ reporters available, complementary to mito-RP, that would enable simultaneous monitoring of $\mathrm{pH}_{\mathrm{m}}$ and $\left[\mathrm{Ca}^{2+}\right]_{\mathrm{c}}$ transients during motor activity. The cyclical changes in $\mathrm{pH}_{\mathrm{m}}$ seen in Figure $6 D$ (left section) were common but unanticipated and occurred without obvious changes in $\left[\mathrm{Ca}^{2+}\right]_{\mathrm{m}}$. Unlike rhod-FF (Fig. $6 \mathrm{~B}, \mathrm{C})$, the $\mathrm{Ca}^{2+}$-sensitive wavelength of mito-RP rarely showed discrete jumps that might indicate underlying motor activity, and this may reflect the high affinity of mito-RP $(\sim 1.3 \mu \mathrm{M}$; Nagai et al., 2001) relative to rhod-FF ( $\sim 19 \mu \mathrm{M}$; Invitrogen). The data plotted in Figure $4 E$ show that $\mathrm{pH}_{\mathrm{m}}$ is most responsive in the high end of the $\left[\mathrm{Ca}^{2+}\right]_{\mathrm{m}}$ range reported by mito-RP. Therefore, during endogenous nerve activity, $\left[\mathrm{Ca}^{2+}\right]_{\mathrm{m}}$ levels may persist in a range where mito-RP is close to saturation. To test whether extracellular $\mathrm{Ca}^{2+}$ was required for elevated $\left[\mathrm{Ca}^{2+}\right]_{\mathrm{m}}$ and $\mathrm{pH}_{\mathrm{m}}$ levels during endogenous activity, $\mathrm{Ca}^{2+}$ was removed from the saline. As expected, $\left[\mathrm{Ca}^{2+}\right]_{\mathrm{m}}$ fell (420 nm excitatory trace rose) and $\mathrm{pH}_{\mathrm{m}}$ fell (490 nm excitatory trace fell) (Fig. $6 \mathrm{D}$, right section), suggesting that while $\mathrm{Ca}^{2+}$ had been in the bath the mitochondria had been in an elevated metabolic state associated with elevated $\left[\mathrm{Ca}^{2+}\right]_{\mathrm{m}}$.

\section{Discussion}

In most cells, the ADP:ATP ratio is conventionally accepted as the intrinsic metabolic integrator coordinating the demand of ATP consuming processes with oxidative phosphorylation (Erecińska and Wilson, 1982). In a number of cell types, including neurons, $\mathrm{Ca}^{2+}$ has been reported as an extrinsic regulator of oxidative phosphorylation (McCormack et al., 1990; Balaban, 2002; Kann and Kovacs, 2007), but this has not been demonstrated for individually identified nerve termini, nor has its relevance been established during endogenous nerve activity. On the basis of the data presented here, we suggest that $\left[\mathrm{Ca}^{2+}\right]_{\mathrm{C}}$ coordinates ATP supply with demand in Drosophila motor nerve termini. We show that mitochondria rapidly acquire $\mathrm{Ca}^{2+}$ during nerve stimulation (Fig. 1) and endogenous nerve activity (Fig. 6) and that $\mathrm{Ca}^{2+}$ stimulates mitochondrial energy metabolism (Fig. 2), seen as elevations in $\mathrm{pH}_{\mathrm{m}}, \Delta \psi_{\mathrm{m}}$, and [NA$\mathrm{D}(\mathrm{P}) \mathrm{H}]_{\mathrm{m}}$. The ADP:ATP ratio is rejected as the primary stimulant of mitochondrial energy metabolism in response to nerve stimulation, because changes in $\mathrm{pH}_{\mathrm{m}}$ are profoundly diminished when $\mathrm{Ca}^{2+}$ is replaced with $\mathrm{Sr}^{2+}$ and abolished when either $\mathrm{TPP}^{+}$or KB-R7943 is present to block mitochondrial $\mathrm{Ca}^{2+}$ uptake. Correspondingly, bongkrekic acid, which reduces the availability of $\mathrm{ADP}$ to the $\mathrm{F}_{1} \mathrm{~F}_{0^{-}}$ ATPase, does not diminish the $\mathrm{pH}_{\mathrm{m}}$ elevations that accompany nerve activity.

The increases in $\mathrm{pH}_{\mathrm{m}}, \Delta \psi_{\mathrm{m}}$, and $[\mathrm{NAD}(\mathrm{P}) \mathrm{H}]_{\mathrm{m}}$ indicate an increase in the capacity of presynaptic mitochondria to produce ATP and is thus analogous to an increase in oxidative phosphorylation. The elevation of these measures in response to nerve activity is not consistent with an invariant rate of oxidative phosphorylation, as all three measures rose despite the transient fall in $\Delta \psi_{\mathrm{m}}$ and an increase in demand for ATP. Similarly, it is unlikely that an extramitochondrial source of ATP (glycolysis) has the capacity to reverse any presynaptic ATP deficit within seconds to inflate mitochondrial $\Delta \psi_{\mathrm{m}}, \mathrm{pH}_{\mathrm{m}}, \mathrm{d}[\mathrm{NAD}(\mathrm{P}) \mathrm{H}]_{\mathrm{m}}$. However, until techniques become available to measure oxygen consumption, the utilization of mitochondrial metabolic substrates, or ATP production in presynaptic termini, we cannot directly substantiate the effect of $\mathrm{Ca}^{2+}$ on presynaptic oxidative phosphorylation or ATP production.

Studies in mice have shown that, in neurons and/or glia, electrical stimulation leads to a rapid decrease in $\mathrm{NAD}(\mathrm{P}) \mathrm{H}$ fluorescence followed by a sustained increase (Kasischke et al., 2004; Reinert et al., 2004). However, debate continues regarding which cell types and subcellular compartments are responsible for this increase and how many cell types or subcellular compartments produce the biphasic signals in $\mathrm{NAD}(\mathrm{P}) \mathrm{H}$ levels. The data presented here show that the increase in oxidative phosphorylation occurs in neurons, and the increase in $\mathrm{NAD}(\mathrm{P}) \mathrm{H}$ levels arises 
predominantly in mitochondria rather than the cytosol (Fig. $1 H, I)$.

Mito-RP and mtAlpHi have provided the first $\mathrm{pH}$ data from presynaptic MN mitochondria in situ. They revealed an unexpectedly rapid $\mathrm{pH}_{\mathrm{m}}$ transient that matched the time of onset and cessation of both mitochondrial $\mathrm{Ca}^{2+}$ uptake and depolarization (Fig. $1 E, F)$. Mitochondrial depolarization is consistent with $\mathrm{Ca}^{2+}$ entering the mitochondrion, but the TMRE data shown in this study indicate that $\Delta \psi_{\mathrm{m}}$ starts regenerating the moment $\left[\mathrm{Ca}^{2+}\right]_{\mathrm{m}}$ peaks. The time of onset of $\Delta \psi_{\mathrm{m}}$ regeneration indicates that at the $\left[\mathrm{Ca}^{2+}\right]_{\mathrm{m}}$ peak, $\mathrm{Ca}^{2+}$ (positive charge) entry to the mitochondrion either ceases or comes into balance with phosphate entry, which precipitates $\mathrm{Ca}^{2+}$ in the matrix. Mitochondrial alkalization is consistent with oxidative phosphorylation being stimulated by $\mathrm{Ca}^{2+}$, but its speed of onset, matching the onset of mitochondrial $\mathrm{Ca}^{2+}$ uptake, was not anticipated. Based on the stoichiometry of the calcium-phosphate complex formed in the matrix $\left[\mathrm{Ca}_{3}\left(\mathrm{PO}_{4}\right)_{2}\right]$, where uptake of one $\mathrm{Ca}^{2+}$ is accompanied by the generation and net extrusion of one proton (Chalmers and Nicholls, 2003), rapid acidification might well have been predicted. Rapid alkalization, however, suggests that $\mathrm{Ca}^{2+}$ entry to the mitochondrion may be in partial exchange for protons $\left(\mathrm{H}^{+}\right)$. The latter mechanism is consistent with the two phases observed, where the initial $\mathrm{pH}_{\mathrm{m}}$ spike $\left(\mathrm{Ca}^{2+} / \mathrm{H}^{+}\right.$exchange) is coincident with $\mathrm{Ca}^{2+}$ uptake, which then collapses to give way to a smaller sustained elevation in $\mathrm{pH}_{\mathrm{m}}\left(\mathrm{Ca}^{2+}\right.$ stimulated ETC activity).

Unique to this study, we linked $\mathrm{Ca}^{2+}$-stimulated mitochondrial energy metabolism with endogenous nerve activity in individually identified $\mathrm{MN}$ termini by using electrophysiological techniques during fictive locomotion (Fig. 3) and subsequent fluorometric techniques across a range of frequencies (Figs. $4-6)$. Not only does $\left[\mathrm{Ca}^{2+}\right]_{\mathrm{c}}$ rise to levels at which mitochondria rapidly acquire $\mathrm{Ca}^{2+}$ during endogenous nerve activity (Fig. $6 \mathrm{~B}, \mathrm{C})$, but surprisingly $\left[\mathrm{Ca}^{2+}\right]_{\mathrm{c}}$ levels are very similar between MNs when they fire at their endogenous rates (Fig. $5 C$ ) despite large differences in these rates (Fig. $3 \mathrm{~B}, \mathrm{C}$ ). As $\left[\mathrm{Ca}^{2+}\right]_{\mathrm{c}}$ is a supralinear function of axon firing frequency for any given neuron (Tank et al., 1995), we had expected $\left[\mathrm{Ca}^{2+}\right]_{\mathrm{c}}$ levels to be considerably higher in faster firing MNs when operating at their native firing frequencies. The apparent mitochondrial affinities for $\mathrm{Ca}^{2+}\left(K_{\text {app }}\right)$ are also similar in different MNs (Fig. $5 D$ ). We speculate that evolutionary pressures may be responsible for the proximity of $\left[\mathrm{Ca}^{2+}\right]_{\mathrm{c}}$ values $(\sim 330 \mathrm{~nm})$ to $K_{\text {app }}$ values $(\sim 280 \mathrm{~nm})$ due to advantages inherent in harnessing the $\mathrm{Ca}^{2+}$ dependence of mitochondrial energy metabolism in $\mathrm{MN}$ termini. Our data can reveal little about whether $K_{\text {app }}$ adjusted to accommodate $\left[\mathrm{Ca}^{2+}\right]_{\mathrm{c}}$ levels or vice versa, but as $\left[\mathrm{Ca}^{2+}\right]_{\mathrm{c}}$ has adjusted to a similar level in different MNs despite different firing rates, we favor the hypothesis that $\mathrm{MN}$ termini have adapted to accommodate the common $K_{\text {app }}$ of their mitochondria.

We propose that mitochondrial $\mathrm{Ca}^{2+}$ uptake from the cytosol is pivotal for stimulating oxidative phosphorylation and that the ADP:ATP ratio, or other feedback mechanisms, may only play a minor role in coordinating presynaptic ATP supply with demand. Our study has focused on the period during and immediately following short stimulus trains, encompassing tens of seconds, where changes in $\mathrm{pH}_{\mathrm{m}}, \Delta \psi_{\mathrm{m}}$, and $[\mathrm{NAD}(\mathrm{P}) \mathrm{H}]_{\mathrm{m}}$ are most pronounced. Nevertheless, $\mathrm{Ca}^{2+}$-stimulated presynaptic mitochondrial energy metabolism over longer periods of time remains to be examined. For example, is this mechanism called upon to a greater degree in those MNs with a high work rate? The data in Figures $4 D$ indicate that this may be the case because, at endogenous firing rates, mitochondria in fast-firing MN13Ib fill more rapidly with $\mathrm{Ca}^{2+}$ than those in slow-firing MN6/7Ib. As there was no indication of mitochondrial $K_{\text {app }}$ being higher in MN13Ib (Fig. $5 D$ ), it may be that $\left[\mathrm{Ca}^{2+}\right]_{\mathrm{c}}$ rises to marginally higher levels in faster firing MNs. However, although trends consistent with this hypothesis were observed in two independent datasets (Fig. 5C), the trends were not significant. Reconciliation of these datasets might be found in the understanding that $\left[\mathrm{Ca}^{2+}\right]_{\mathrm{m}}$ has a second power dependence on $\left[\mathrm{Ca}^{2+}\right]_{\mathrm{c}}$ (Nicholls and Ferguson, 2002), and the acceptance that our estimates of $\left[\mathrm{Ca}^{2+}\right]_{\mathrm{c}}$ may lack the resolution to resolve small differences between $\mathrm{MN}$ termini. Whatever the reason for $\left[\mathrm{Ca}^{2+}\right]_{\mathrm{m}}$ being driven higher in MN13Ib during endogenous activity, higher levels of mitochondrial energy metabolism seem to be a risky longterm condition as they are associated with higher rates of production of reactive oxygen species (Nicholls, 2008), while outright mitochondrial failure has devastating consequences (Mattson et al., 2008). An alternative strategy to support high work rates would be to increase presynaptic mitochondrial density, but data on presynaptic density are not available for Drosophila larvae.

The proximity of the average $K_{\text {app }}$ value for mitochondrial $\mathrm{Ca}^{2+}$ uptake $(\sim 280 \mathrm{~nm}$; Fig. $5 D)$ to $\left[\mathrm{Ca}^{2+}\right]_{\mathrm{c}}$ at native firing frequencies ( $\sim 330 \mathrm{~nm}$; Fig. $5 \mathrm{C})$ might suggest that mitochondrial $\mathrm{Ca}^{2+}$ uptake limits $\left[\mathrm{Ca}^{2+}\right]_{\mathrm{c}}$ in different MNs. In Drosophila larval $\mathrm{MNs}$, however, this is not the case. Both genetic and pharmacological approaches have shown that during short stimulus trains like those used here, $\left[\mathrm{Ca}^{2+}\right]_{\mathrm{c}}$ levels are not affected by the absence of functional mitochondria (Guo et al., 2005; Chouhan et al., 2010). If not mitochondrial $\mathrm{Ca}^{2+}$ uptake, then what mechanism establishes the ceiling for presynaptic $\left[\mathrm{Ca}^{2+}\right]_{\mathrm{c}}$ during endogenous activity? While this study does not reveal the mechanism, we speculate that either the plasma membrane ATPase (PMCA) or the Slowpoke channel might play a role. PMCA may limit $\left[\mathrm{Ca}^{2+}\right]_{\mathrm{c}}$, as it has been shown to clear most of the $\mathrm{Ca}^{2+}$ from these termini (Lnenicka et al. 2006). In termini without mitochondria and thus without the high ATP production rates conferred by oxidative phosphorylation, there may be sufficient reserves of ATP to power the PMCA over the duration of short stimulus trains, but ATP levels are likely to deplete over longer durations, and $\left[\mathrm{Ca}^{2+}\right]_{c}$ would be expected to rise. Indeed, $\left[\mathrm{Ca}^{2+}\right]_{\mathrm{c}}$ levels do rise during sustained stimulus trains in the absence of presynaptic mitochondria (Guo et al., 2005; Verstreken et al. 2005). On the other hand, the Slowpoke channel may also contribute to enforcing a ceiling for $\left[\mathrm{Ca}^{2+}\right]_{\mathrm{c}}$ because this $\mathrm{K}^{+}$channel will open as $\left[\mathrm{Ca}^{2+}\right]_{\mathrm{c}}$ increases (Elkins et al., 1986), which in turn suppresses plasma membrane excitability.

In the lizard $\mathrm{MN}$ terminal, nerve stimulation drives down both presynaptic $\mathrm{NAD}(\mathrm{P}) \mathrm{H}$ levels and $\Delta \psi_{\mathrm{m}}$ (Talbot et al., 2007; 2008), and although both recover once stimulation ceases, there is little indication of the overshoot seen in Drosophila MN termini. It would be interesting to know how $50 \mathrm{~Hz}$ stimulus trains of 10-50 s duration used in the studies on lizard MNs compare to the endogenous activity of lizard MNs and what happens in response to less prolonged trains. The differences between Drosophila and lizard MNs are especially intriguing, as some reports have indicated that intramitochondrial dehydrogenases of invertebrates lack sensitivity to $\mathrm{Ca}^{2+}$ (McCormack and Denton, 1981). Given the diversity in terminal types in both vertebrate and invertebrate nervous systems, it seems likely that mitochondrial $\mathrm{Ca}^{2+}$ uptake will prove to be important for stimulating mitochondrial energy metabolism in other nerve termini. 


\section{References}

Abad MF, Di Benedetto G, Magalhães PJ, Filippin L, Pozzan T (2004) Mitochondrial $\mathrm{pH}$ monitored by a new engineered green fluorescent protein mutant. J Biol Chem 279:11521-11529.

Aberle H, Haghighi AP, Fetter RD, McCabe BD, Magalhães TR, Goodman CS (2002) wishful thinking encodes a BMP type II receptor that regulates synaptic growth in Drosophila. Neuron 33:545-558.

Attwell D, Laughlin SB (2001) An energy budget for signaling in the grey matter of the brain. J Cereb Blood Flow Metab 21:1133-1145.

Balaban RS (2002) Cardiac energy metabolism homeostasis: role of cytosolic calcium. J Mol Cell Cardiol 34:1259-1271.

Brand AH, Perrimon N (1993) Targeted gene expression as a means of altering cell fates and generating dominant phenotypes. Development 118:401-415.

Chalmers S, Nicholls DG (2003) The relationship between free and total calcium concentrations in the matrix of liver and brain mitochondria. J Biol Chem 278:19062-19070.

Chance B, Williams GR (1955) Respiratory enzymes in oxidative phosphorylation. I. Kinetics of oxygen utilization. J Biol Chem 217:383-393.

Chouhan AK, Zhang J, Zinsmaier KE, Macleod GT (2010) Presynaptic mitochondria in functionally different motor neurons exhibit similar affinities for $\mathrm{Ca}^{2+}$ but exert little influence as $\mathrm{Ca}^{2+}$ buffers at nerve firing rates in situ. J Neurosci 30:1869-1881.

Cortassa S, Aon MA, Marbán E, Winslow RL, O’Rourke B (2003) An integrated model of cardiac mitochondrial energy metabolism and calcium dynamics. Biophys J 84:2734-2755.

David G, Barrett EF (2003) Mitochondrial $\mathrm{Ca}^{2+}$ uptake prevents desynchronization of quantal release and minimizes depletion during repetitive stimulation of mouse motor nerve terminals. J Physiol 548:425-438.

Denton RM (2009) Regulation of mitochondrial dehydrogenases by calcium ions. Biochim Biophys Acta 1787:1309-1316.

Dietzl G, Chen D, Schnorrer F, Su KC, Barinova Y, Fellner M, Gasser B, Kinsey K, Oppel S, Scheiblauer S, Couto A, Marra V, Keleman K, Dickson BJ (2007) A genome-wide transgenic RNAi library for conditional gene inactivation in Drosophila. Nature 448:151-156.

Duchen MR (1992) $\mathrm{Ca}^{2+}$-dependent changes in the mitochondrial energetics in single dissociated mouse sensory neurons. Biochem J 283:41-50.

Elkins T, Ganetzky B, Wu CF (1986) A Drosophila mutation that eliminates a calcium-dependent potassium current. Proc Natl Acad Sci U S A 83:8415-8419.

Erecińska M, Wilson DF (1982) Regulation of cellular energy metabolism. J Membr Biol 70:1-14.

Filippin L, Magalhães PJ, Di Benedetto G, Colella M, Pozzan T (2003) Stable interactions between mitochondria and endoplasmic reticulum allow rapid accumulation of calcium in a subpopulation of mitochondria. J Biol Chem 278:39224-39234.

Filippin L, Abad MC, Gastaldello S, Magalhães PJ, Sandonà D, Pozzan T (2005) Improved strategies for the delivery of GFP-based $\mathrm{Ca}^{2+}$ sensors into the mitochondrial matrix. Cell Calcium 37:129-136.

Greenawalt JW, Carafoli E (1966) Electron microscope studies on the active accumulation of Sr+ + by rat-liver mitochondria. J Cell Biol 29:37-61.

Grynkiewicz G, Poenie M, Tsien RY (1985) A new generation of $\mathrm{Ca}^{2+}$ indicators with greatly improved fluorescence properties. J Biol Chem 260:3440-3450.

Guo X, Macleod GT, Wellington A, Hu F, Panchumarthi S, Schoenfield M, Marin L, Charlton MP, Atwood HL, Zinsmaier KE (2005) The GTPase dMiro is required for axonal transport of mitochondria to Drosophila synapses. Neuron 47:379-393.

Haller M, Mironov SL, Karschin A, Richter DW (2001) Dynamic activation of $\mathrm{K}_{\mathrm{ATP}}$ channels in rhythmically active neurons. J Physiol 537:69-81.

He T, Lnenicka GA (2011) $\mathrm{Ca}^{2+}$ buffering at a Drosophila larval synaptic terminal. Synapse 65:687-693.

Hendel T, Mank M, Schnell B, Griesbeck O, Borst A, Reiff DF (2008) Fluorescence changes of genetic calcium indicators and OGB-1 correlated with neural activity and calcium in vivo and in vitro. J Neurosci 28:7399-7411.

Henderson PJ, Lardy HA (1970) Bongkrekic acid. An inhibitor of the adenine nucleotide translocase of mitochondria. J Biol Chem 245: $1319-1326$.

Hoang B, Chiba A (2001) Single-cell analysis of Drosophila larval neuromuscular synapses. Dev Biol 229:55-70.
Jiang D, Zhao L, Clapham DE (2009) Genome-wide RNAi screen identifies Letml as a mitochondrial $\mathrm{Ca}^{2+} / \mathrm{H}^{+}$antiporter. Science 326:144-147.

Kann O, Kovács R (2007) Mitochondria and neuronal activity. Am J Physiol Cell Physiol 292:C641-657.

Kann O, Schuchmann S, Buchheim K, Heinemann U (2003) Coupling of neuronal activity and mitochondrial metabolism as revealed by $\mathrm{NAD}(\mathrm{P}) \mathrm{H}$ fluorescence signals in organotypic hippocampal slice cultures of the rat. Neuroscience 119:87-100.

Kasischke KA, Vishwasrao HD, Fisher PJ, Zipfel WR, Webb WW (2004) Neural activity triggers neuronal oxidative metabolism followed by astrocytic glycolysis. Science 305:99-103.

Klingenberg M (2008) The ADP and ATP transport in mitochondria and its carrier. Biochim Biophys Acta 1778:1978-2021.

Klose MK, Chu D, Xiao C, Seroude L, Robertson RM (2005) Heat shockmediated thermoprotection of larval locomotion compromised by ubiquitous overexpression of Hsp70 in Drosophila melanogaster. J Neurophysiol 94:3563-3572.

Kosterin P, Kim GH, Muschol M, Obaid AL, Salzberg BM (2005) Changes in FAD and NADH fluorescence in neurosecretory terminals are triggered by calcium entry and by ADP production. J Membr Biol 208:113-124.

Kumar A, Rotter S, Aertsen A (2010) Spiking activity propagation in neuronal networks: reconciling different perspectives on neural coding. Nat Rev Neurosci 11:615-627.

Lin DM, Goodman CS (1994) Ectopic and increased expression of Fasciclin II alters motoneuron growth cone guidance. Neuron 13:507-523.

Lnenicka GA, Grizzaffi J, Lee B, Rumpal N (2006) $\mathrm{Ca}^{2+}$ dynamics along identified synaptic terminals in Drosophila larvae. J Neurosci 26:12283-12293.

Macleod GT, Hegström-Wojtowicz M, Charlton MP, Atwood HL (2002) Fast calcium signals in Drosophila motor neuron terminals. J Neurophysiol 88:2659-2663.

Mattson MP, Gleichmann M, Cheng A (2008) Mitochondria in neuroplasticity and neurological disorders. Neuron 60:748-766.

McCormack JG, Denton RM (1981) A comparative study of the regulation of $\mathrm{Ca}^{2+}$ of the activities of the 2-oxoglutarate dehydrogenase complex and $\mathrm{NAD}^{+}$-isocitrate dehydrogenase from a variety of sources. Biochem J 196:619-624.

McCormack JG, Osbaldeston NJ (1990) The use of the Ca2(+)-sensitive intramitochondrial dehydrogenases and entrapped fura- 2 to study $\mathrm{Sr}^{2+}$ and $\mathrm{Ba}^{2+}$ transport across the inner membrane of mammalian mitochondria. Eur J Biochem 192:239-244.

McCormack JG, Halestrap AP, Denton RM (1990) Role of calcium ions in regulation of mammalian intramitochondrial metabolism. Physiol Rev 70:391-425.

Moreno-Sánchez R (1985) Contribution of the translocator of adenine nucleotides and the ATP synthase to the control of oxidative phosphorylation and arsenylation in liver mitochondria. J Biol Chem 260:12554-12560.

Nagai T, Sawano A, Park ES, Miyawaki A (2001) Circularly permuted green fluorescent proteins engineered to sense $\mathrm{Ca}^{2+}$. Proc Natl Acad Sci U S A 98:3197-3202.

Nicholls DG (2008) Oxidative stress and energy crises in neuronal dysfunction. Ann N Y Acad Sci 1147:53-60.

Nicholls DG, Ferguson SJ (2002) Bioenergetics 3, 3rd Ed. London: Academic.

Reinert KC, Dunbar RL, Gao W, Chen G, Ebner TJ (2004) Flavoprotein autofluorescence imaging of neuronal activation in the cerebellar cortex in vivo. J Neurophysiol 92:199-211.

Robb-Gaspers LD, Burnett P, Rutter GA, Denton RM, Rizzuto R, Thomas AP (1998) Integrating cytosolic calcium signals into mitochondrial metabolic responses. EMBO J 17:4987-5000.

Santo-Domingo J, Vay L, Hernández-Sanmiguel E, Lobatón CD, Moreno A, Montero M, Alvarez J (2007) The plasma membrane $\mathrm{Na}^{+} / \mathrm{Ca}^{2+}$ exchange inhibitor KB-R7943 is also a potent inhibitor of the mitochondrial $\mathrm{Ca}^{2+}$ uniporter. Br J Pharmacol 151:647-654.

Scaduto RC Jr, Grotyohann LW (1999) Measurement of mitochondrial membrane potential using fluorescent rhodamine derivatives. Biophys J 76:469-477.

Talbot JD, Barrett JN, Barrett EF, David G (2008) Rapid, stimulationinduced reduction of C12-resorufin in motor nerve terminals: linkage to mitochondrial metabolism. J Neurochem 105:807-819. 
Talbot J, Barrett JN, Barrett EF, David G (2007) Stimulation-induced changes in NADH fluorescence and mitochondrial membrane potential in lizard motor nerve terminals. J Physiol 579:783-798.

Tang Y, Zucker RS (1997) Mitochondrial involvement in post-tetanic potentiation of synaptic transmission. Neuron 18:483-491.

Tank DW, Regehr WG, Delaney KR (1995) A quantitative analysis of presynaptic calcium dynamics that contribute to short-term enhancement. J Neurosci 15:7940-7952.

Territo PR, Mootha VK, French SA, Balaban RS (2000) $\mathrm{Ca}^{2+}$ activation of heart mitochondrial oxidative phosphorylation: role of the $\mathrm{F}_{0} / \mathrm{F}_{1}$-ATPase. Am J Physiol Cell Physiol 278:C423-C435.

Verstreken P, Ly CV, Venken KJ, Koh TW, Zhou Y, Bellen HJ (2005) Synaptic mitochondria are critical for mobilization of reserve pool vesicles at Drosophila neuromuscular junctions. Neuron 47:365-378.
Ward MW, Huber HJ, Weisová P, Düssmann H, Nicholls DG, Prehn JH (2007) Mitochondrial and plasma membrane potential of cultured cerebellar neurons during glutamate-induced necrosis, apoptosis, and tolerance. J Neurosci 27:8238-8249.

Wiederkehr A, Park KS, Dupont O, Demaurex N, Pozzan T, Cline GW, Wollheim CB (2009) Matrix alkalinization: a novel mitochondrial signal for sustained pancreatic beta-cell activation. EMBO J 28: 417-428.

Wingrove DE, Gunter TE (1986) Kinetics of mitochondrial calcium transport. II. A kinetic description of the sodium-dependent calcium efflux mechanism of liver mitochondria and inhibition by ruthenium red and by tetraphenylphosphonium. J Biol Chem 261:15166-15171.

Yoshikami D, Okun LM (1984) Staining of living presynaptic nerve terminals with selective fluorescent dyes. Nature 310:53-56. 